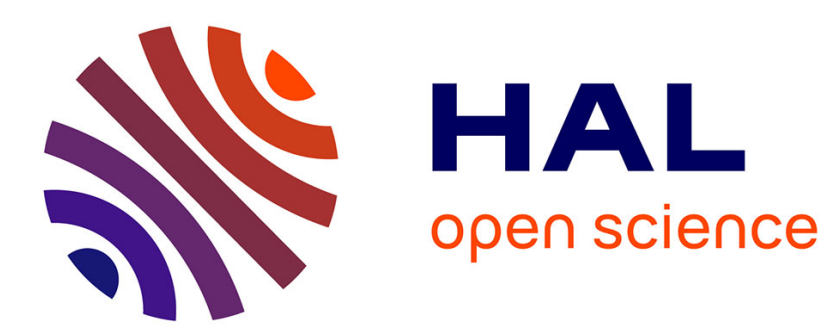

\title{
Laser-assisted cold spray (LACS)
}

Dimitris K. Christoulis, Michel Jeandin, Eric Irissou, Jean-Gabriel Legoux, Wolfgang Knapp

\section{To cite this version:}

Dimitris K. Christoulis, Michel Jeandin, Eric Irissou, Jean-Gabriel Legoux, Wolfgang Knapp. Laserassisted cold spray (LACS). D.C. Dumitras. NdYAG laser, InTech, pp.59-96, 2012, 10.5772/2000 . hal-00685037

\section{HAL Id: hal-00685037 \\ https://hal-mines-paristech.archives-ouvertes.fr/hal-00685037}

Submitted on 13 Jan 2015

HAL is a multi-disciplinary open access archive for the deposit and dissemination of scientific research documents, whether they are published or not. The documents may come from teaching and research institutions in France or abroad, or from public or private research centers.
L'archive ouverte pluridisciplinaire HAL, est destinée au dépôt et à la diffusion de documents scientifiques de niveau recherche, publiés ou non, émanant des établissements d'enseignement et de recherche français ou étrangers, des laboratoires publics ou privés. 


\title{
Laser-Assisted Cold Spray (LACS)
}

\author{
Dimitris K. Christoulis' ${ }^{1}$, Michel Jeandin ${ }^{1}$, \\ Eric Irissou ${ }^{2}$, Jean-Gabriel Legoux ${ }^{2}$ and Wolfgang Knapp ${ }^{3}$ \\ ${ }^{1}$ MINES-ParisTech, Centre des Matériaux/CNRS.-U.M.R. 7633, \\ C2P-Competence Center for spray Processing \\ ${ }^{2}$ National Research Council Canada - Industrial Materials Institute, Montreal, QC \\ ${ }^{3}$ CLFA-Fraunhofer-ILT, Paris \\ 1,3France \\ ${ }^{2}$ Canada
}

\section{Introduction}

Thermal spray processes are used for the formation of metallic, ceramic and composite coatings. In thermal spray techniques, atomization jets or process gasses are used to melt or partially melt and to accelerate the feedstock powder or droplet material towards a prepared substrate (Davis, 2004). The feedstock itself may be in powder, rod or wire form. Upon impact, a bond forms with the surface, with subsequent particles causing thickness build-up and forming a lamellar structure. Thermal sprayed coatings are applied in various industrial sectors: automotive industry (Barbezat, 2005; Barbezat, 2006), marine industry (Wood et al., 2004), biomedical applications (Guipont et al. 2002, Liu et al., 2009) and aeronautical/aerospace applications (Dorfman et al., 2004; Evans et al., 2006) to name a few. Nevertheless, the deposition of coatings by thermal spraying technologies presents several disadvantages: high oxygen concentration, high porosity, non-uniform microstructure due to unmelted particles, quenching and thermal stresses, complex processes difficulties to retain the initial microstructure of the sprayed powder, low deposition efficiency. In order to minimize these defects and improve the properties of the coatings, techniques which control accurately the spray conditions (pressure and composition of the spraying chamber atmosphere, surrounding gas, temperature, power, etc.) have been developed (Sarafoglou et al., 2007).

However, these problems of conventional thermal sprayed coatings can be minimized or eliminated by employing Cold Gas Dynamic Spraying (Cold Spray), which is the newest process of the thermal spray techniques. Cold Spray is a solid state process where powder particles are accelerated by a low temperature supersonic gas stream and are plastically deformed upon impact on a substrate to form a coating. The formation of coatings by means of cold spray, compared with the conventional sprayed coatings has the major advantage of the absence of macroscopic melting of the sprayed particles. This leads to coatings which do not present quenching and thermal stresses. Also, cold-sprayed coatings retain the initial microstructure of the powder.

In thermal spray, coating adhesion strength is paramount since advanced coatings must remain bonded to the substrate under various and severe conditions. The same 
requirements of high coating adhesion hold true for cold spray coatings. However, the bonding mechanism of cold sprayed particles has not been completely clarified. Experimentally, it has been shown, that the particles can bond and form a coating only if they exhibit a material-dependant critical velocity (Schmidt et al., 2009). This critical velocity depends also on surface conditions (Ajdelsztajn et al., 2006; Golesich et al., 2008). The appropriate preparation of substrate surface prior to cold spraying contributes to the formation of high adhesive coatings. The adhesion of cold sprayed coatings can be increased by means of conventional methods such as grit-blasting and chemical solvents etching. However, grit-blasting may provoke contamination of the substrate by grit inclusions, which in turns can decrease the fatigue resistance while chemical solvents etching generates hazardous waste and is environmentally unfriendly (Garcia-Alonso et al., 2011).

Cold spray was coupled with a nano-pulsed Nd-YAG laser leading to the development of the Laser-Assisted Cold Spray (LACS) process which is a novel process, for the pretreatment of the substrate and the coatings build-up. This leads to the production of advanced protective coatings of high adhesion and cohesion strength. At this pioneering stage, LACS was used for the formation of aluminum cold-sprayed coatings substrates onto aluminum alloy substrates (AISI-2107) and Ni-20Cr coatings onto Inconel718 substrates. Coatings adhesion strength was measured by using another Nd-YAG laser (i.e. LAser Shock Adhesion Testing, namely LASAT ${ }^{\circledR}$ ). LASATesting ${ }^{\circledR}$ was shown to be a powerful tool for studying local adhesion of coatings and for determining the influence of metallurgical and morphological interface features on adhesion

\section{Cold Spray technology}

Cold Gas Dynamic Spraying (Cold Spray) is the newest process of thermal spray techniques. The cold spray process was initially developed in the mid-1980s at the Institute for Theoretical and Applied Mechanics of the Siberian Division of the Russian Academy of Science (Irissou et al., 2008a) but was introduced in laboratory level to North America and Europe only in the 2000s. Contrary to the conventional thermal spray technologies (plasma spraying, HVOF, arc-spraying etc), Cold Spray is characterized by a low spraying particle temperature and high spraying particle velocity (Figure 1). The main advantage of the Cold Spray technology, compared with the conventional thermal spraying techniques, is the absence of the macroscopic melting of the spraying particles. In Cold Spray technology, the sprayed particles are heated in temperature below their melting point and they are accelerated to supersonic velocities. Thus, the sprayed particles are plastically deformed upon impact on a substrate to form a coating. This leads to coatings where common problems of conventional thermal spray technologies, like high-temperature oxidation, evaporation, melting, crystallization, residual stresses, debonding, gas release, and other common problems for conventional thermal spray methods are minimized or eliminated (Papyrin et al., 2008).

In cold spray, fine powders in the 5 and $50 \mu \mathrm{m}$ range are generally used. However, in some cases, coarser powders can be cold sprayed under appropriate conditions (Van Steenkiste et al., 1999; Van Steenkiste et al., 2002; Christoulis et al., 2011; Li et al., 2008)

In practice, the principle of the cold spray process can be described as follows. The powder is supplied to the nozzle by a high pressure carrier gas. The kinetic energy of the particles is 
increased by the propellant gas which can be heated between $200^{\circ} \mathrm{C}$ and $850^{\circ} \mathrm{C}$. In the most of the cases, the feeding and the propellant gases are of the same nature. The gases which are used are nitrogen $\left(\mathrm{N}_{2}\right)$, Helium (He), compressed air, or mixtures of them (Christoulis et al., 2011; Wong et al., 2011; Gartner et al., 2006; Sundararajan et al., 2010; Chavan et al., 2011].

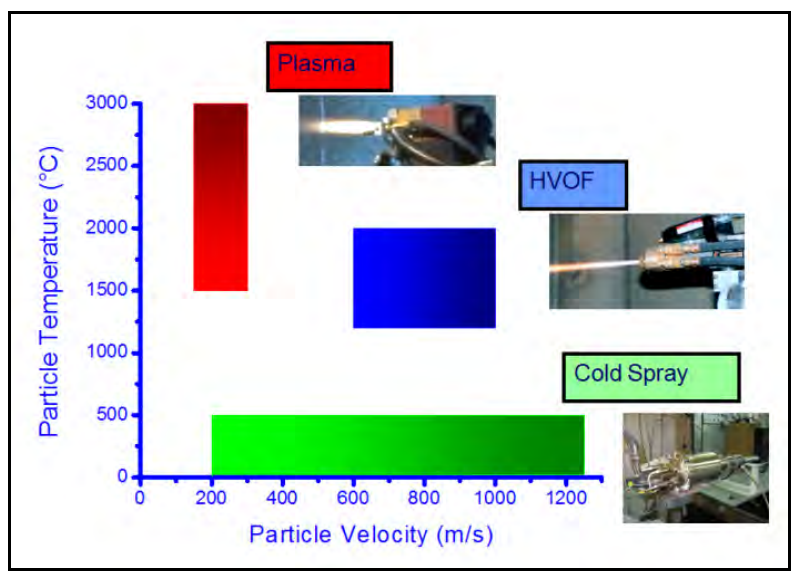

Fig. 1. Cold Spray technology and other conventional thermal spray techniques.

The geometry of the De Laval nozzle (Figure 2) results to the acceleration of the mixture propellant gas-powder at supersonic velocities at the exit of the nozzle. Although the gas temperature may seem high at first glance, the divergent of the nozzle causes expansion of gases and therefore a significant lowering of temperature. The powder particles, which also have a very limited residence time in the hot gas flow, in any case remain in a solid or slightly viscous (surface heating).

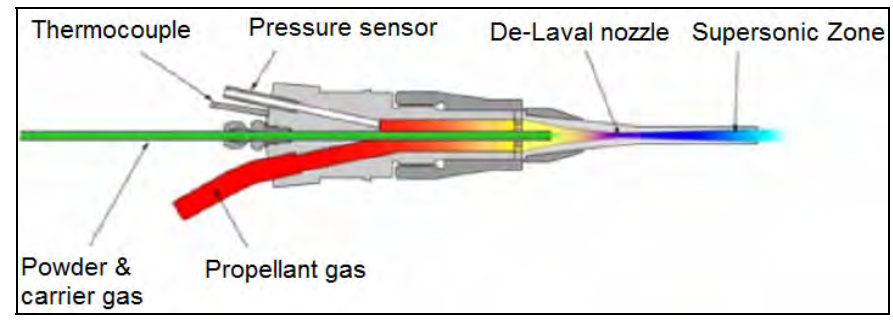

Fig. 2. Gold Spray Gun

\section{Surface pre-treatment}

The formation of advanced coatings is strongly depends on the proper substrate surface pretreatment prior to the thermal spraying process. Preparation steps must be undertaken correctly in order the coatings to perform the design expectations, otherwise, a total failure could occur (Davis, 2004).

Coating adhesion is connected directly with the surface pre-treatment of the substrate. In thermal spray, coating adhesion strength is paramount since coatings can only fulfill its 
function if it remains bonded to the substrate under various and severe conditions. Many studies are devoted to the bonding mechanisms and to the optimization and improvement of coating bond strength in thermal spray (Greving et al., 1994; Brandt, 1995 ; Lu et al., 2002 ; Araujo et al., 2005 ; Day et al., 2005).

The same requirements of high coating adhesion hold true for cold spray coatings. However, the cold spray process differs from other thermal spray processes in its bonding mechanisms since there is no macroscopic melting of the feedstock powder. It is often concluded that the cold-sprayed particles adhere only on "nascent" surfaces (Ichikawa et al., 2008) produced by the impacts of high-velocity sprayed particles which provoke the fracture of the pre-existing oxide layers of the substrate. However, the "cleaning" of substrate by sprayed particles can be characterized as an accidental method which induces the waste of the costly powders.

The major surface preparation techniques which are currently carried out in thermal spraying technology are presented in the next two paragraphs. The first paragraph includes the main conventional techniques, while the second one presents the most innovate laser pre-treatment technologies.

\subsection{Conventional techniques}

In thermal spraying technology, coating adhesion can be increased by means of conventional methods (i.e grit-blasting, chemical etching, formation of bond-coatings). It should be mentioned that the decreasing of the substrates surface is important and it should be realized before grit-blasting. The decreasing of the substrate is performed to remove contaminants such as oil, grease, paint, rust, scale, and moisture. The decreasing of the surfaces is carried out either by using chemical solvents (aceton, MEEK etc) either by using hot vapor (Davis, 2004).

Grit-blasting is the most common technique which is used as a preparation method in conventional thermal spray processes (Bahbou et al., 2004; Peredes et al., 2006 ; Bobzin et al., 2010 ; Gonzalez-Hermosilla et al., 2010). In the case of cold spray process, it is often claimed that the substrates do not require any surface preparation; the substrates can be used in their as-received state after the necessary cleaning (Kroemmer et al., 2006; Hartmann, 2010). However, the grit-blasting of the substrates is accomplished in various application of cold spraying process in order to enhance the adhesion of the coatings (Richer et al., 2006; Koivuluoto et al., 2007; Bala et al., 2010 ; Koivuluoto et al., 2010). Experimental results of cold-sprayed copper onto copper substrates have shown that the coatings adhesion strength is significantly higher on grit-blasted substrates (36.0 MPa) compared to the coatings adhesion strength onto as-received substrates (5.4 MPa) (Makinen et al., 2007). Contrary, in the case of cold sprayed titanium, experimental results have shown that the bond strength of titanium cold sprayed coatings is higher onto polished substrates compared to grit-blasted substrates (Marrocco et al., 2006). Generally, in thermal spraying technology the increase of the substrate roughness via grit-blasting is a common procedure. Usually coating adhesion is correlated with the mean arithmetic roughness $\left(R_{a}\right)$ of the substrates. However, it seems that $\left(R_{a}\right)$ is not enough (Zecchino, 2003) for the characterization of a roughened surface and also it has still not been clarified which characteristics of the roughness influence the coatings' adhesion (Fukanuma et al., 2003). Furthermore, grit-blasting may provoke 
contamination of the substrate by grit inclusions which can be catastrophic for some applications. In automotive industry, which is a predominant sector for the application of thermal spray technology (Barbezat, 2005; Barbezat, 2007), for the production of engine blocks with thermally sprayed cylinder, other techniques should be used for the preparation of the substrate since the grit can remain within the many internal passages of the engine block. The grit can come loose during operation and later cause engine breakdowns (Schlaefer et al., 2008). Also, it is should be referred that grit-blasting is environmentally unfriendly and also it can be unhealthy for the operators of grit-blasting apparatus since the grits have been correlated with serious diseases such as silicosis, aluminosis, lung scarring, pneumoconiosis, or emphysema (Petavratzi et al., 2005).

Other techniques which are used for the pre-treatment of the substrate are the water-jet, the chemical etching (Pawlowski, 2008) and the macroroughening (Davis, 2004). Water-jet pretreatment has been used in the case of shrouded plasma sprayed MCrAlY coatings onto nickel superalloys (i.e Inconel 718, Rene 80 and Mar-M 509) (Pawlowski, 2008). The surface of the substrate is roughened by the water-jet, and it was used since the morphology of a water-jet treated surface is much finer than that of a sand-blasted one (Pawlowski, 2008).

Chemical etching with various acids (sulfuric, nitric, or hydrochloric acid) is another pretreatment method of the metallic substrates, which was used to modify the roughness of the substrate and thus to increase the adhesion of the thermal sprayed coatings. However, it is not used so often any more due to environmental reasons.

Also, it should be mentioned that the application of a bond-coatings is also another pretreatment method of the substrate. Of course the bond coats applied over grit-blasted surfaces (Davis, 2004). However bond coatings are applied in order to enhance coatings adhesion, in the cases that the coating cannot adhere directly to the substrate. In gas turbines technology, bond coatings (MCrAlY) are applied before the formation of the thermal barrier coatings (Padture et al., 2002; Saral et al., 2009; Zhang et al., 2009)

\subsection{Laser techniques}

Thermal spray and laser processing can be considered as half brothers since they show many common features due to the use of a (more or less) high-energy source for both (Jeandin et al., 2010). Their combination can therefore be very fruitful and prominent to achieve coatings, which results in their most recent and advanced applications (Jeandin et al., 2010).

Laser thermal spray hybrid processes have been developed as a result of the successful combination of laser and thermal spray technologies. Various types of laser have been combined with the guns of thermal spray process. Combining laser processing to thermal spray resulted in a major improvement for thermal spray in 3 sub-areas, i.e. that of pretreatment, that of post-treatment and that of simulation of thermal and kinetic phenomena. In the next two paragraphs (\$3.2.1 and §3.2.2), advanced laser pre-treatment methods are presented while section 4 is devoted to laser techniques which have been developed for the simulation of thermal and kinetic phenomena appeared in thermal spray technology. The post-treatment methods are not examined in the current chapter. 


\subsubsection{Laser heating and/or cleaning}

The laser pretreatment of the substrates can provoke the ablation and/or the heating of the substrates. The interaction mechanisms which will appear between laser and matter (substrate) depend on the substrate material, the interaction time and the power density of the laser (Garcia-Alonso et al., 2011). The cleaning of the substrate form dust, oil, and contaminants is achieved by the ablation. Also, ablation can eliminate the superficial native oxide layers of the substrate which prevent the metallurgical bonding between the sprayed particles and the substrate allowing better particles/substrate contact which results in improved interfacial adhesion.

Laser pretreatment can provoke also the preheating of the substrate. Experiments have shown that the increased temperature of the substrate can lead to formation of coatings with improved properties (Gartner et al., 2006; Sundararajan et al., 2010). The preheating of the substrate can be achieved also by conventional methods (furnace or by passing the thermal spray gun over the substrate). However, the conventional methods are not fully controlled and also can provoke undesired phenomena (intensive oxidation or distortions of the material).

In early 2000's Zieris et al. developed the Laser Assisted Atmospheric Plasma Spraying (LAAPS) (Zieris et al., 2003). LAAPS has been developed by the combination of the gun of the Atmospheric Plasma Spraying with diode or Nd-YAG laser.

In LAAPS technology, three different arrangements between laser beam and plasma torch are possible (figure 3). Depending on the application the appropriate arrangement is selected. In the first case (figure 3a) the laser beam precedes the plasma torch and it acts as a pre-treatment method. The laser creates a molten pool crater at the substrate surface and thus the sprayed particles impinge on the molten substrate and form a coating that is metallurgically bonded to the substrate (Zieris et al., 2004). In the second arrangement (figure $3 b$ ), the laser beam is concentric with the plasma torch while in the third arrangement (figure 3c), which can be characterized as a post-treatment method the laser beam follows the plasma torch

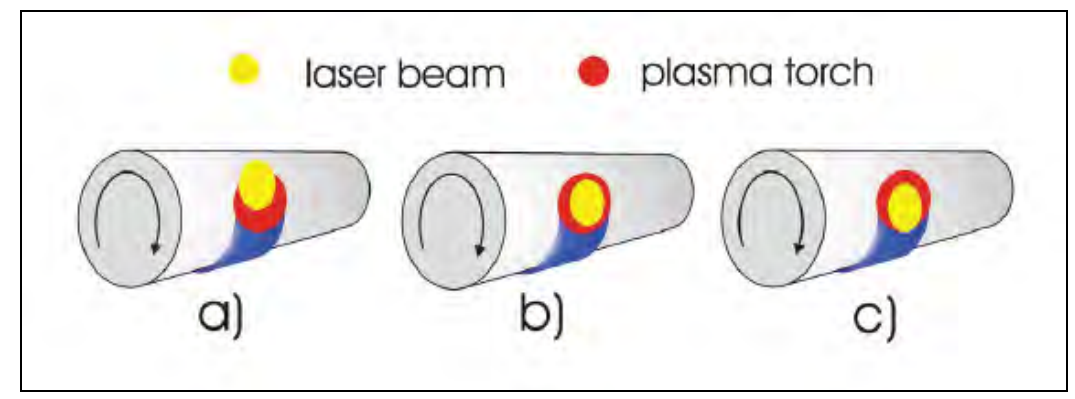

Fig. 3. Possible arrangements for laser thermal spray spots, after R. Zieris et al., 2003 (Zieris et al., 2003). The rotating cylinder is the substrate where the coating is deposited.

Two different LAAPS coatings were examined (Zieris et al., 2003); NiCrSiB onto mild steel substrates and $\mathrm{Al}_{2} \mathrm{O}_{3}-3 \% \mathrm{TiO}_{2}$ coatings onto Inconel 718 substrate. Coatings were created on grit-blasted substrates as well as onto laser pre-treated substrates. For $\mathrm{NiCrSiB}$ sprayed 
coatings, the plasma spray gun was coupled with a laser diode (power of $2 \mathrm{~kW}$ ) and it was found that the adhesion strength of $\mathrm{NiCrSiB}$ was $\sim 50 \mathrm{MPa}$ onto grit-blasted substrates while it was increase at $\sim 260 \mathrm{MPa}$ in the case of laser ablated substrates. Similarly, in the case of $\mathrm{Al}_{2} \mathrm{O}_{3}-3 \% \mathrm{TiO}_{2}$, the adhesion strength of the coating was increased by using LAAPS $(\sim 30$ $\mathrm{MPa}$ onto as-received substrates) instead of conventional APS ( $10 \mathrm{MPa}$ onto grit-blasted substrates). For $\mathrm{Al}_{2} \mathrm{O}_{3}-3 \% \mathrm{TiO}_{2}$, the plasma spray gun was coupled with $\mathrm{Nd}-\mathrm{YaG}$ laser (power of 1 or $4 \mathrm{~kW}$ ). Advanced coatings of AlSi30 (Zieris et al., 2004) and $\mathrm{ZrO}_{2}-8 \% \mathrm{Y}_{2} \mathrm{O}_{3}$ (Dubourt et al., 2006) has been successfully deposited by employing LAAPS.

Formerly, the PROTAL® (French acronym for "PROjection Thermique Assisté par Laser", i.e: Laser Assisted Thermal Spray) technology comprises a method where pulsed laser (Qswitched Nd-YAG laser) irradiates the substrate surface prior to the deposition of the sprayed particles. It should be referred that PROTAL® is employed only as a pre-treatment method of the substrate. Thus, this case the laser treatment always precedes the spraying deposition. The purpose, of the laser irradiation is to eliminate the contaminations films and oxide layers, to generate a surface state enhancing deposit adhesion and to limit the recontamination of the deposited layer by condensed vapors (Costil et al., 2004a).

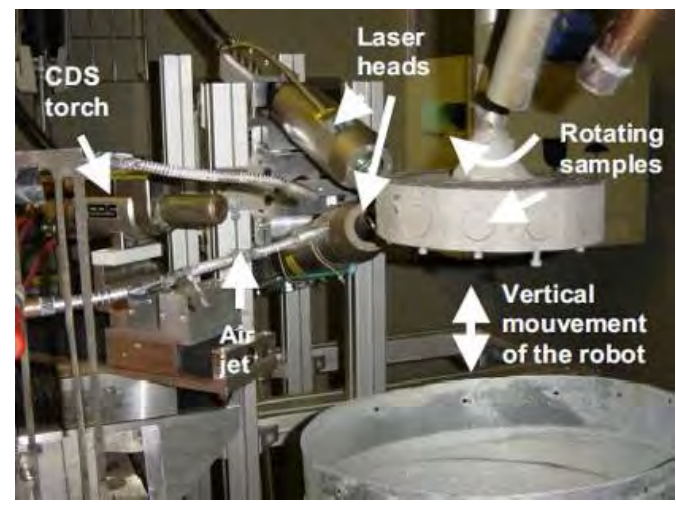

(a)

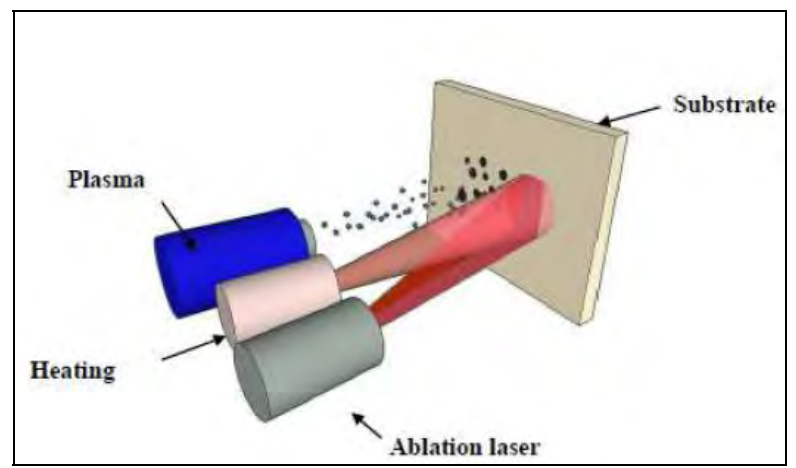

(b)

Fig. 4. (a) PROTAL® coupled to HVOF gun by Costil et al. (Costil et al., 2004a) (b) Two NdYAG lasers coupled with a plasma spray gun by Danlos et al. (Danlos et al., 2011) 
The PROTAL® is equipped with two Q-switched Nd-YAG lasers operating at $\lambda=1.064 \mu \mathrm{m}$ with an average power output of $40 \mathrm{~W}$ each $(270 \mathrm{~mJ}$ per pulse with adjustable frequency up to $150 \mathrm{~Hz}$ ) and with a pulse duration (FWHM) of approximately $10 \mathrm{~ns}$. The laser beam has a rectangular shape with a "top-hat" energy distribution thanks to a specific optical arrangement (Costil et al., 2004a).

The PROTAL® technology has been used already successfully in thermal spray technology (i.e. Plasma spraying, HVOF) (Barradas et al., 2004; Costil et al., 2004b) (figure 4a). Costil et al. (Costil et al., 2004b) have shown that in the case of plasma sprayed Ni-Al onto al-alloy substrate (AISI 2017), PROTAL® coatings can show higher adhesion strength compared to coatings formed onto substrates pretreated by conventional methods (i.e. grit-blasting).

Recently, Danlos et al. (Danlos et al., 2011) coupled two pulsed Nd-YAG lasers with a plasma spray gun (figure $4 \mathrm{~b}$ ). In this configuration the first Nd-YAG laser was used in order to heat the substrate and the second one (PROTAL® laser head) was used to ablate the substrate. The heating Nd-YAG laser was a pulsed millisecond laser with a wavelength of $1064 \mathrm{~nm}$, while the ablation laser was a pulsed nanosecond laser with the same wavelength of $1064 \mathrm{~nm}$. In order to impose both laser treatments simultaneously, the same frequency of $60 \mathrm{~Hz}$ was chosen for both heating and ablation laser. By using this set-up Ni-5Al coatings were deposited onto two different substrate; Al-alloy substrate (AISI-2017) and Ti-alloy substrate (Ti-6Al-4V). The substrates were pre-treated by conventional method (decreasing and grit-blasting) as well as by employing the set-up of figure 4a. For this combination of materials, it was found that the coatings adhesion was higher onto gritblasted substrates. It seems that the higher surface roughness which induced by the gritblasting, can explain the higher adhesion level onto the gritblasted substrates [47].

\section{Adhesion determination of thermal sprayed coatings by employing laser techniques}

The formation of thermal sprayed coatings can be divided into two stages: the creation of the first layer onto the substrate and the building-up of the coating itself onto as-sprayed layers. During the creation of the first layer, the adhesion of thermal sprayed particles onto the substrate influences strongly the bond strength of the cold sprayed coatings. The individual thermal sprayed particles (splat) is the basic structural building block in thermal sprayed coatings (Davis, 2004) and thus the study of these individual particles can give answers to fundamental queries about thermal sprayed coatings (Moreau et al., 1995; Christoulis et al., 2006; McDonald et al., 2006).

Furthermore, on macro-scale level, the characterization of the bond strength of thermal sprayed coatings is of high interest. Adhesion is a property of major concern for thermal spray coatings, because it is necessary for the coating to adhere to the substrate throughout the design life of the coating system (Davis, 2004).

Two laser techniques have been developed to determine the adhesion level, either of individual sprayed particles, or of thermal sprayed coatings. LASERFLEX which is presented in the first paragraph of this section shed light on the adhesion mechanism of thermal sprayed particle. At a macroscopic level characterization and quantitative determination of the bond strength of the cold sprayed coatings take place due to the development of a, one my say, unique test, i.e. Laser Shock Adhesion Test, namely LASAT ${ }^{\circledR}$. 


\subsection{LASERFLEX (Laser Shock Flier Impact Experiments)}

LASER shock Flier impact Experiments (LASERFLEX) (Barradas et al., 2007; Ichikawa et al., 2007a), primarily laser shock spallation can be used as an innovative technique to simulate experimentally the influence of "in-flight" material velocity and temperature on adhesion phenomena at the impact. LASERFLEX (figure 5) is a high-velocity impact simulation test that uses laser shock accelerated foil to impact on a substrate. Laser shock flier impact experiments consisted in high velocity cladding of a foil (the flier which simulates the coldsprayed particle) onto bulk material (which acts as a substrate). The foils are accelerated by the laser shock at high velocity similar to the velocity of cold sprayed particle and then the foils impact on "substrates" at high velocity.

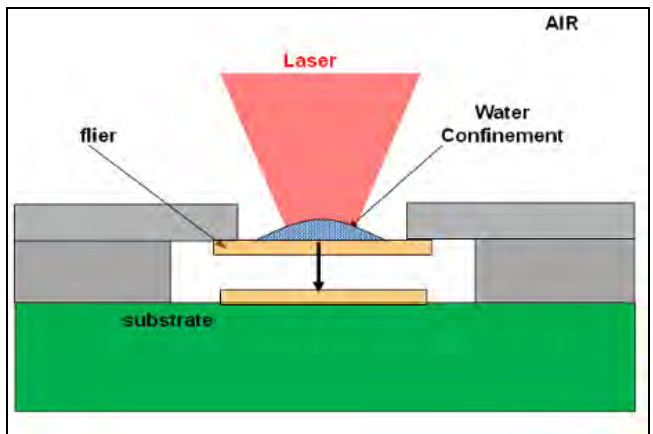

(a)

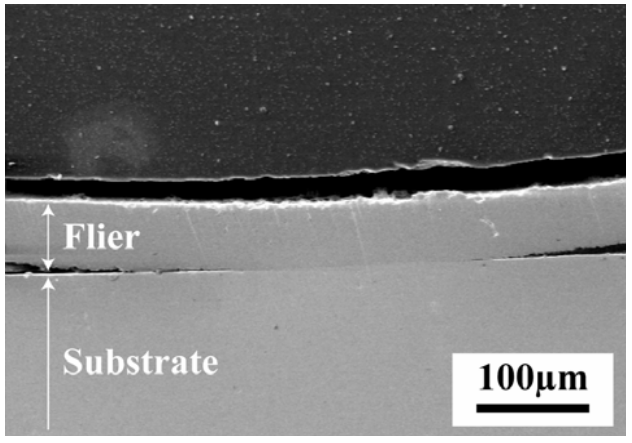

(b)

Fig. 5. (a) Schematic illustration of the LASERFLEX (Barradas et al., 2007), (b) CoNiCrAlY flier deposited onto Inconel 615 substrate by employing LASERFLEX (Ichikawa et al., 2007a).

The flier is stuck to the steel sample holder horizontally due to a mere thin layer of grease, which left a distance to fly before reaching bulk substrate (Ichikawa et al., 2007a). For the shock, a one-shot laser beam from a Nd:YAG laser operating at $20 \mathrm{~J}$ during $20 \mathrm{~ns}$ focused on the foil in a spot of $4 \mathrm{~mm}$ in diameter. A transparent medium to the laser, i.e., water, was deposited at the surface of the sample. It led to a confining of the shock on the sample and increased the shock pressure and time so that the beam-matter interaction was extended to $50 \mathrm{~ns}$.

The LASERFLEX technique has been used for the study of deposition of $\mathrm{Cu}$ flier onto $\mathrm{Al}$ substrate (Barradas et al., 2007) and CoNiCrAlY flier onto Inconel 615 substrate (Ichikawa et al., 2007a), revealing complicated phenomena which affect the coating-substrate adhesion. In the case of $\mathrm{Cu}$ flier onto $\mathrm{Al}$ substrate (Barradas et al., 2007) by using LASERFLEX evidence of local melting at the substrate-particle interface and the creation of intermetallics. The simulation of cold-sprayed particles by employing LASERFLEX, revealed that also in cold spraying, which is a solid state process, melting in micro level scale can be present in the interaction mechanism particle-substrate. On the other hand, in the case of the CoNiCrAlY flier onto Inconel 615, LASERFLEX revealed that the adhesion requires higher in-flight velocity and specific phase combination at the interface between flier and substrate (Ichikawa et al., 2007a). In this case, there is no evidence of melting of the flier or substrate. 


\subsection{LASAT (LAser Shock Adhesion Test)}

LASAT is a laser innovative technique which has been developed for the determination of the adhesion and/or the cohesion of thermal sprayed coatings. LASAT has already been used to characterize the adhesion of thermal sprayed coatings (Barradas et al., 2004; Barradas et al., 2005; Boileau et al., 2005;Ichikawa et al., 2007b) and splat (isolated thermal sprayed particles) (Guetta et al., 2009). These experimental results have shown that LASATesting is a powerful tool for studying local adhesion of coatings and for determining the influence of metallurgical and morphological interface features on adhesion. Recently, LASAT was used also for other type of coatings and not only for thermal sprayed coatings. LASAT was applied successfully for the adhesion characterization of coatings which have been produced by EB-PVD (Fabre et al., 2011).

For the potted history, one may refer to shot peening as a process which was formerly applied to coatings (Al clads of aircrafts parts in this case) to characterize adhesion (Jeandin et al., 2003). The principle of this, one may say somewhat archaic, test was to shear the coating-substrate interface from coating plastic deformation due to peening effect. Above a certain peening level, coating spalling off can occur, which corresponds to a qualitative approximate adhesion limit.

In a similar way, the LASATesting was developed based on the use of a laser shock. The principle of the LASAT technology is presented in figure 6a. Irradiating the surface of a substrate with a high-power laser can generate a shock wave, the propagation of which leads to a tensile stress at the coating-substrate interface. This results from the crossing of the incident release wave with its reflected (at the reverse side, i.e. at the coating surface) release wave. To determine the adhesion strength, laser shocks are applied to samples at different levels of the incident laser power flux (figure $6 \mathrm{~b}$ ). The de-bonding limit, i.e. when exceeding the interface resistance, is inferred from coating surface velocity vs time profile obtained by Doppler laser interferometry using a VISAR ("Velocity Interferometer System for Any Reflector"). The adhesion strength is then given through simulation of the loading profile.

Below and above the laser shock adhesion threshold, two types of different velocity profiles of the coating surface are respectively achieved (figure 6b).

The two types of velocity signals show significant peaks in the velocity amplitude, which correspond to the interaction of the shock wave with the coating surface. In the curve typical of a laser flux below the threshold, the time between two subsequent peaks is that for the shock wave to propagate through the whole coated substrate material and go back. Therefore, the wave can go through the interface, which is the sign there is no interfacial damage.

The second typical shape of coating surface velocity profile is that recorded for a laser flux which is above the threshold (figure 6b). In this case, the distance between two velocity peaks is shorter and the time between the two peaks corresponds to the time necessary for the wave to cross two times the coating only. This signal is typical of de-bonding at the interface as the shock wave reflects on the void which was created at the first interaction with the interface. 


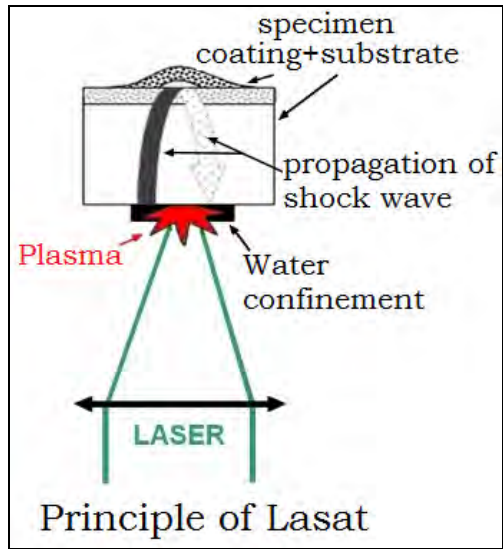

(a)

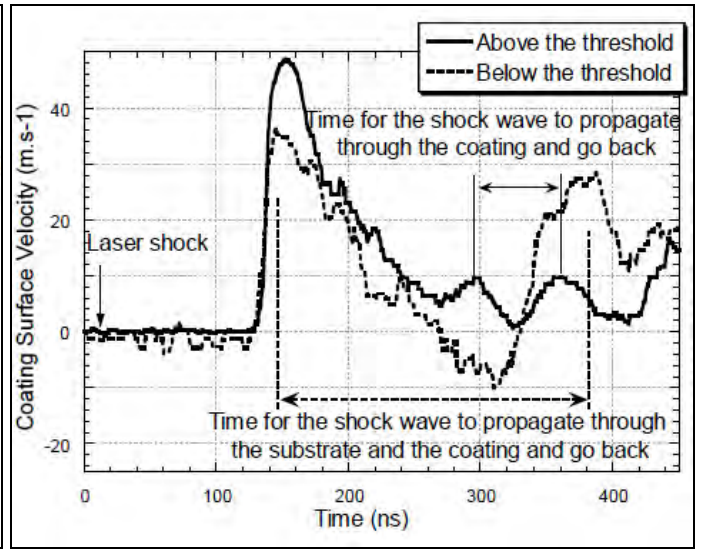

(b)

Fig. 6. (a) Principle of LASAT, (b) Typical coating surface velocity vs time VISAR profiles, below (dotted) and above (plain) the laser shock adhesion threshold (Jeandin et al., 2003)

This interpretation of the velocity profiles, as for soundness criteria of the interface, was ascertained by metallographical studies of cross-sections of as-shocked specimens. Adhesion tests can therefore be interpreted using velocity signal diagnostics only.

Incidentally, LASATesting is based on a purely-mechanical process, which is different from (and more efficient than) other shock-based adhesion tests which, however, involve thermal phenomena and remain rather limited in their exploitation (Costil et al., 2001; Jeandin et al., 2003).

In contrast with conventional adhesion testing, e.g. "pull-off" testing, LASATesting can detect, in particular, the influence of well-defined microstructural features including those of a small size (below $1 \mu \mathrm{m}$ typically) and/or of a given shape.

\section{Laser-Assisted Cold Spray (LACS)}

Laser Assisted Cold Spray (LACS) process combined laser pretreatment of the substrate and the coatings build-up in one step for the production of advanced protective or functional coatings of high adhesion and cohesion strength. Nowadays, to improve adhesion strength, conventional substrate pre-treatment are generally performed before applying the cold spray coating. This include grit-blasting that is performed prior to spraying. Often time, the grit blasting procedure requires masking of the part to protect the regions that are not intended to be coated. The grit blasting procedure results in the inclusion of small grit particles at the interface between the coating and substrate. This limits its use when fatigue properties are important. In addition, grit blasting produces waste and can be harmfull to the operator as discussed in section 3.1. The cohesive strength is improved by thermal posttreatments however, this adds another step in the production of a protective or functional coating but more importantly, in some cases, this procedure would hinder one of the advantages of the cold spray process which is to preserve the structure characteristics of the powder (i.e. nanostrcure, phases, etc.). The conventional techniques for the improvement of 
adhesion and cohesion techniques are two, three or even four step process while the coupling of cold spray system with a laser permits the creation of dense coatings with high bond strength and cohesion in a mere one-step process.

Bray et al. (Bray et al., 2009) coupled a laser diode of wavelength $980 \mathrm{~nm}$ with a cold spray gun (figure 7$)$. In this case titanium powder $(<45 \mu \mathrm{m})$ was sprayed onto mild steel substrates. The laser diode had a heating effect on the substrate, which was beneficial for the formation of the cold sprayed coatings. It was found that as the substrate temperature increased by the irradiation of the tlaser laser diode, the deposition efficiency of the titanium coatings increased, while the coatings porosity decreased.

In another configuration (figure 8), a pulsed Nd-YAG laser was coupled with the cold-spray gun to result in the laser beam passing milliseconds prior to the cold-spray jet for deposition, (Christoulis et al., 2009; Christoulis et al. 2010). Pulsed Nd-YAG laser were operated only during the first pass in order to clean the substrate surface. By using the experimental set-up of figure 8 two coating systems were studied: Aluminum and Ni-20Cr onto an Al-based

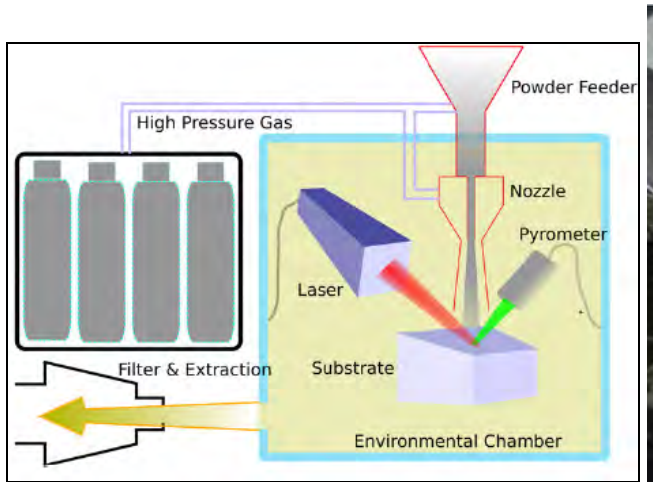

(a)

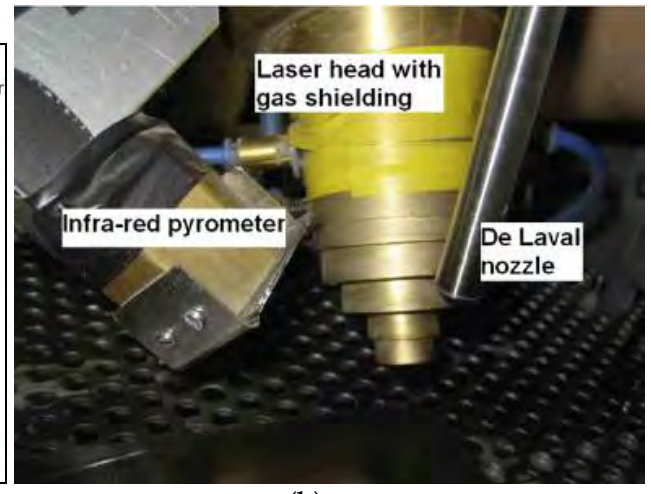

(b)

Fig. 7. (a) Experimental set-up, (b) side view of experimental set-up (Bray et al., 2009).

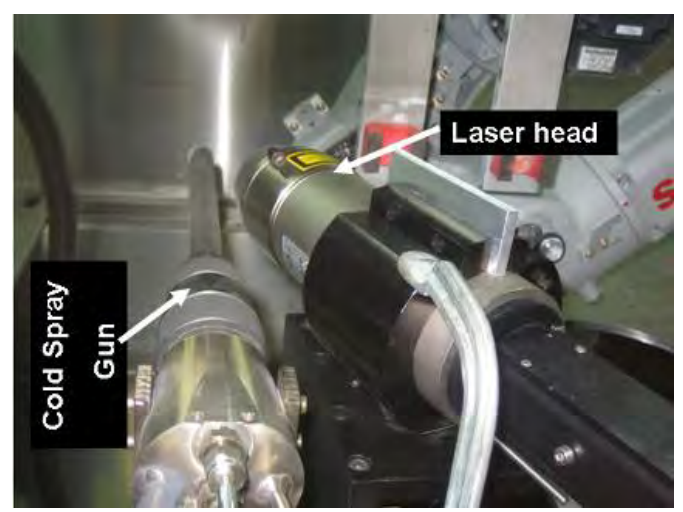

(a)

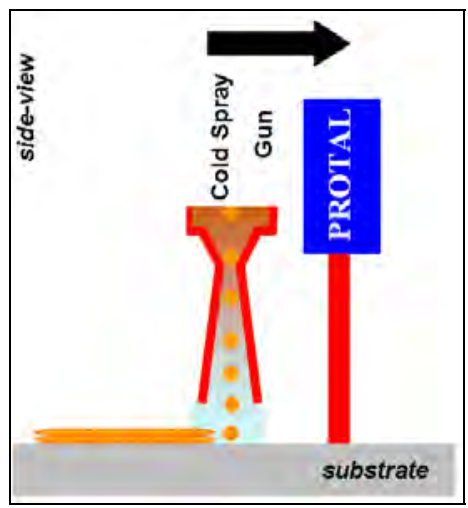

(b)

Fig. 8. (a) Experimental set-up, (b) side view of experimental set-up (Christoulis et al., 2009) 
alloy (AISI 2017) and a Ni-based (Inconel718) alloy respectively. The results of these experiments are presented in the next section. The surface preparations and sprayings experiments were carried out in the MAMADC cold spray laboratory located at the Industrial Materials Institute of the National Research Council of Canada.

\section{Application of LACS}

Al-based and Ni-based coatings were formed onto Nd-YAG laser pre-treated substrates as well as onto as-received substrates, and pre-treated by two conventional methods, namely polishing and grit-blasting. It is shown that the coating-substrate interface is significantly improved when pulsed laser ablation is performed at optimized parameters.

The spraying experiments were carried out by using nitrogen $\left(\mathrm{N}_{2}\right)$ as the propelling gas. The cold spraying conditions for both $\mathrm{Al}$ and $\mathrm{Ni20 \textrm {Cr }}$ powders are presented in table 1 . It should be mentioned that the spraying conditions were selected by measuring the particles mean velocity for various standoff distances. The particle velocity was measured by using the ColdSprayMeter ${ }^{\circledR}$ (Tecnar Automation Inc., St-Bruno, QC, Canada) (Christoulis et al., 2009; Christoulis et al., 2010; Jeandin et al. 2010).

Since the Nd-YAG laser was proceeding of the cold spray gun, the scanning of the substrate was realized in a specific way (figure 9a). The same movement geometry was chosen also for the conventionally prepared substrates since experiments indicate that substrate temperature increases during spraying due to the heated propelling gas (Irissou et al., 2008 b). So, a unique movement geometry (figure 9b) was chosen to introduce uniform heat input to all the substrates.

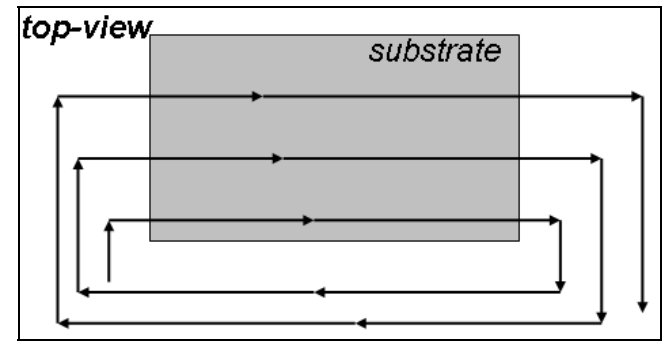

(a)

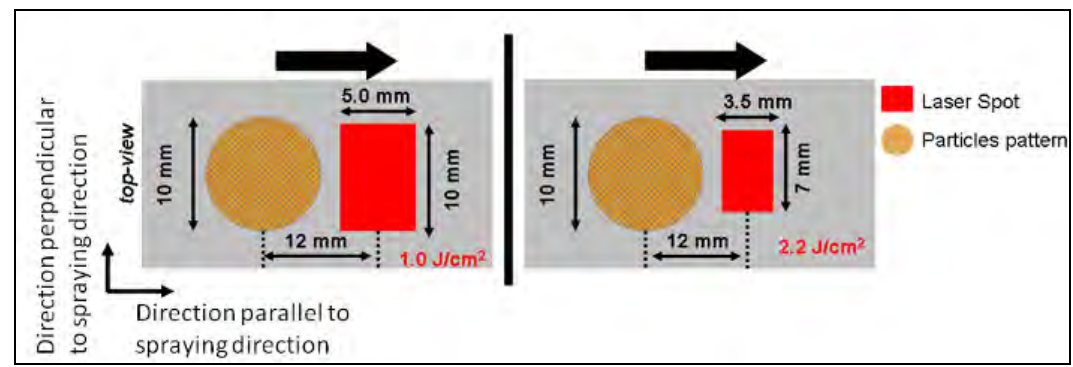

(b)

Fig. 9. (a) movement geometry of coupled cold-spray gun-laser head and (b) top view of the pattern of both cold-sprayed particles and laser spot 
By taking into account, the frequency of the laser, the size of the spot and the movement of the gun (table 1), an arithmetic exercises suffices to calculate the overlapping percentage (table 2). In figure 10, it is shown the overlapped area for two sequential laser pulses for different laser energy and laser frequency. For both laser energies, under the lower laser frequency $(18.75 \mathrm{~Hz})$ no overlapping was created. In this case, inhomogeneous (treated and untreated) areas were created on the substrate (figure 10)

\begin{tabular}{|c|c|c|}
\hline Powder & Al & Ni20Cr \\
\hline \multicolumn{2}{|c|}{ Spraying Conditions } \\
\hline Gas pressure (MPa) & 3.0 & 3.0 \\
\hline Gas temperature $\left({ }^{\circ} \mathrm{C}\right)$ & 350 & 600 \\
\hline Standoff distance (mm) & 20 & 40 \\
\hline Gun traverse speed (mm.s-1) & 100 & 100 \\
\hline \multicolumn{2}{|c|}{ Nozzle Characteristics } \\
\hline Type of the Nozzle & PBI-33 & MOC \\
\hline Exit diameter (mm) & 10 & 2.6 \\
\hline Throat diameter & 2.7 & 6.0 \\
\hline Expansion ratio & 13.7 & 175 \\
\hline Total length (mm) & 220 & \\
\hline
\end{tabular}

Table 1. Experimental Conditions

\begin{tabular}{|c|c|c|c|}
\hline Substrate & Laser energy density $\left(\mathrm{J}^{-\mathrm{cm}^{-2}}\right)$ & Frequency $(\mathrm{Hz})$ & Overlapping of 2 pulses (\%) \\
\hline As-received & No laser & No laser & No laser \\
\hline Polished & No laser & No laser & No laser \\
\hline Grit-blasted & No laser & No laser & No laser \\
\hline As-received & 1.0 & 18.75 & No overlapping \\
\hline As-received & 1.0 & 37.5 & 24 \\
\hline As-received & 1.0 & 150 & 82 \\
\hline As-received & 2.2 & 18.75 & No overlapping \\
\hline As-received & 2.2 & 37.5 & 87 \\
\hline As-received & 2.2 & 150 & 87 \\
\hline
\end{tabular}

Table 2. Pre-treatment of substrates by employing a Nd-YAG laser

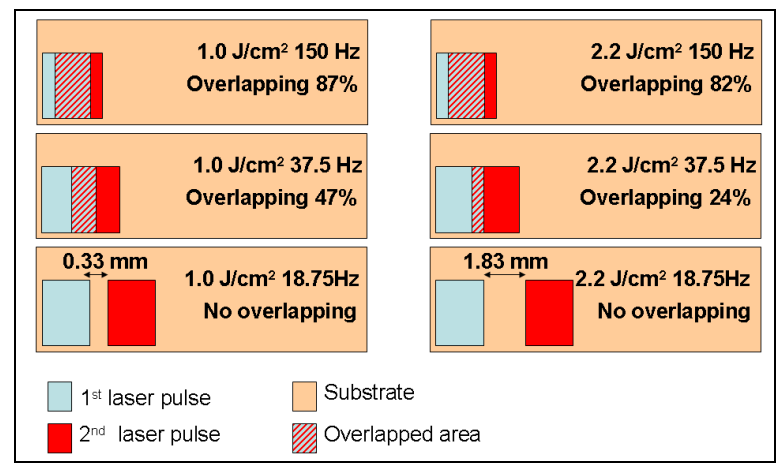

Fig. 10. Overlapping for 2 sequential Nd-YAG laser pulses 


\subsection{Al-based LACS Coatings}

\subsubsection{Materials}

Fine gas-atomized aluminum powder (Alfa Aesar, Massachusetts, USA, 17-35 $\mu \mathrm{m}$ ) of spherical morphology (figure 11a) was sprayed using a KINETICS® 3000-M System (CGT$\mathrm{GmbH}$, Ampfing, Germany). The particle size of the powder was measured by laser granulometry (figure 12b). The microhardness of the powder was measured at $28 \pm 1 \mathrm{HV} 0.01$. The aluminum powder was sprayed onto AISI 2017 aluminum-based alloy.

\subsubsection{Laser irradiation effects}

Cracks and traces, which should have been induced during the production of the hot rolled $\mathrm{Al}$ alloy material, were found on the surface of as-received substrates (figure 12a). The surface of the substrates were observed by employing Scanning Electron Microscope (SEM (LEO 450VP, Germany)).

The observations of the ablated substrate revealed that for low energy density $\left(1.0 \mathrm{~J} . \mathrm{cm}^{-2}\right)$, the pulsed laser beam reacted only with the cracks provoking slight fusion at their borders (white arrows, Figures $3 b$ and $3 c$ ). By comparing figures $3 b$ and $3 c$, it seems that the increase of the laser frequency, provoked a more intensive fusion at the borders of the cracks.

Also, craters were formed after laser irradiation (white circles, figures $3 b$ and $3 c$ ). The craters, are correlated either with the surface defects such as micro-inclusions and small scratches present prior to irradiation or, with the existence of precipitated phases $(\mathrm{Al} 2 \mathrm{Cu})$ of the used AISI 2017 alloy (Costil et al., 2004).

The increase of laser energy density to $2.2 \mathrm{~J} \mathrm{~cm}^{-2}$ resulted in a strong change in surface morphology (figure $3 \mathrm{c}$ and $3 \mathrm{~d}$ ). Extensive substrate melting is observed. The pre-existing cracks disappeared and few craters (white circles, figure $3 c$ ) are still visible. Substrate surface seems to smoothen with the increase in the laser frequency (figure 3d), probably as a result of re-melting which is provoked by the high overlapping phenomenon.

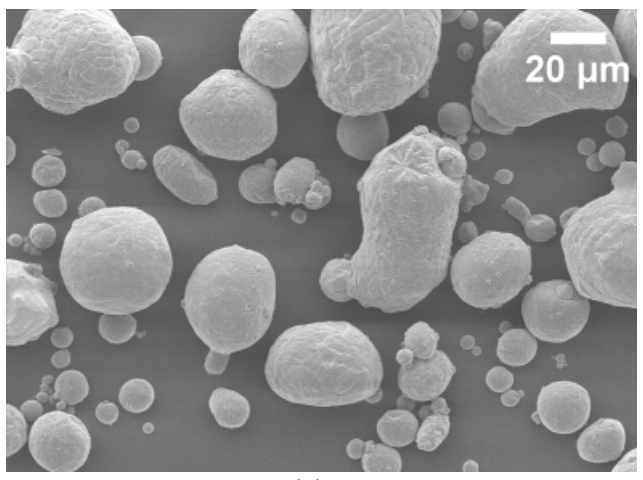

(a)

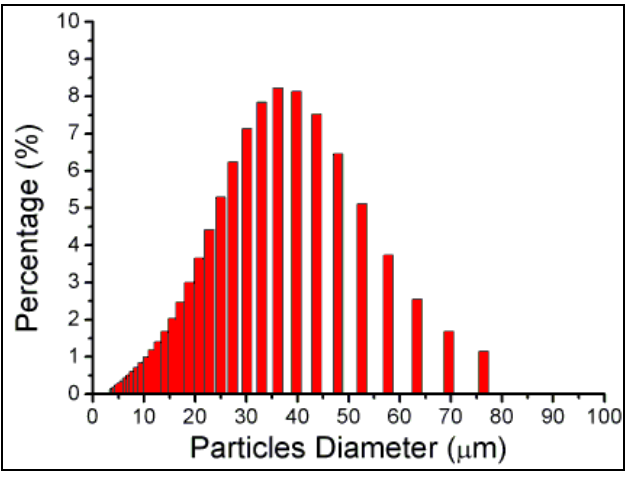

(b)

Fig. 11. (a) SEM of Al powder and (b) Particle distribution by laser analysis. 


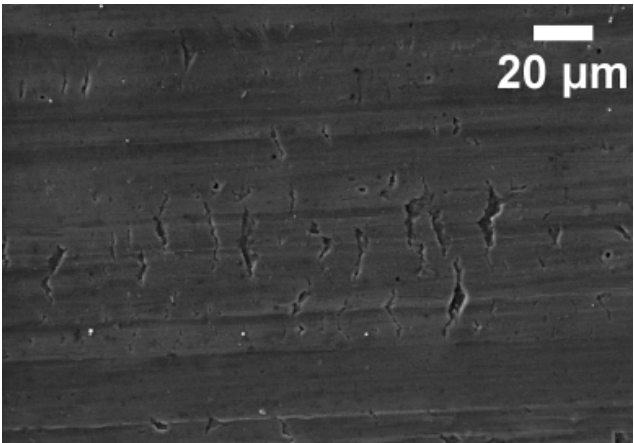

(a)

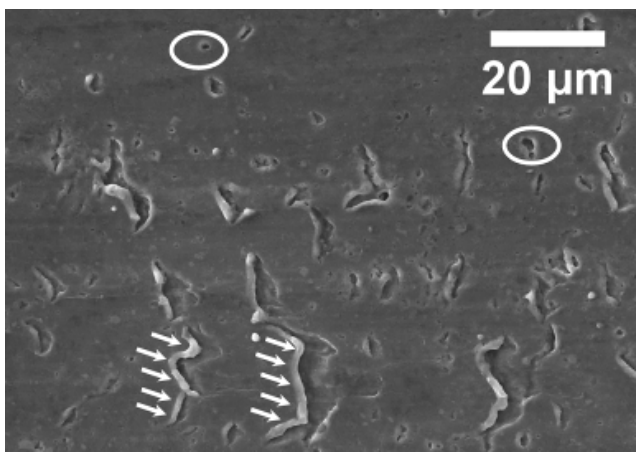

(c)

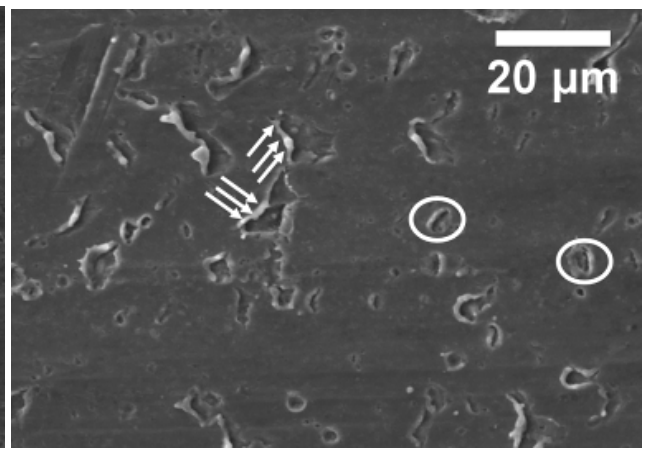

(b)

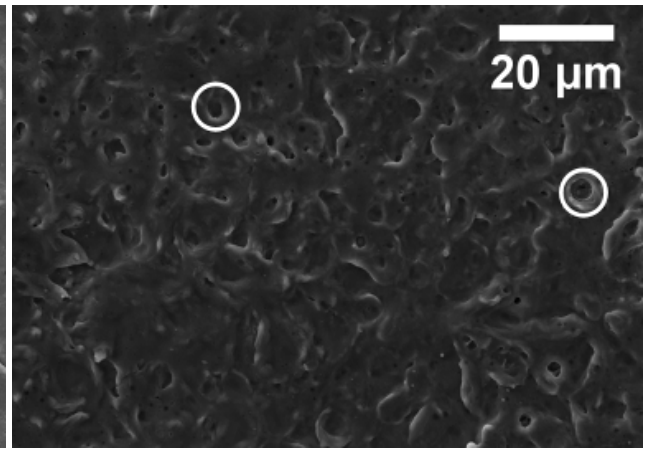

(d)

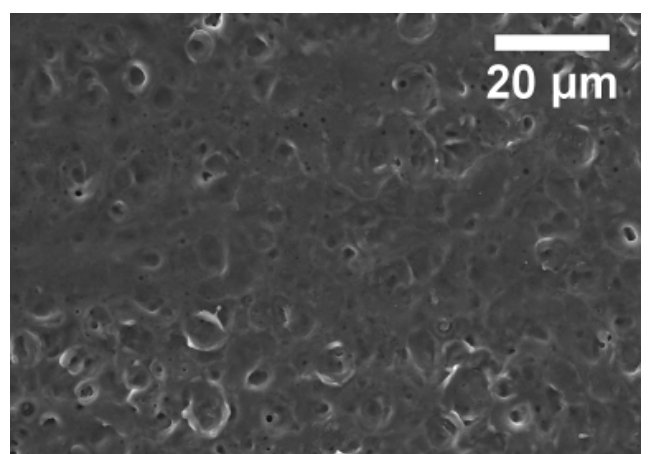

(e)

Fig. 12. SEM top view of AISI-2017 substrate surfaces: (a) un-treated and Nd-YAG laser treated (b) 1.0 J.cm-2, 37.5 Hz., (c) 1.0 J.cm-2, 150 Hz., (d) 2.2 J.cm-2, 37.5 Hz, (e) $2.2 \mathrm{~J} . \mathrm{cm}-2,150 \mathrm{~Hz}$.

\subsubsection{Formation of thick aluminum coatings}

Thick coatings were deposited on the substrates (see figure 13). The mean thickness of the cold-sprayed coatings was also quantitatively calculated via image analysis (ImageJ®) of 
SEM images. Coating mean thicknesses were almost the same for conventionally prepared substrates and for low energy $\left(1.0 \mathrm{~J} . \mathrm{cm}^{-2}\right)$ irradiated substrates (figure 14).

The mean thickness of the coatings was increased significantly as soon as the laser energy density was increased from 1.0 to $2.2{\mathrm{~J} . \mathrm{cm}^{-2}}^{2}$. Interestingly, the difference in coating thickness

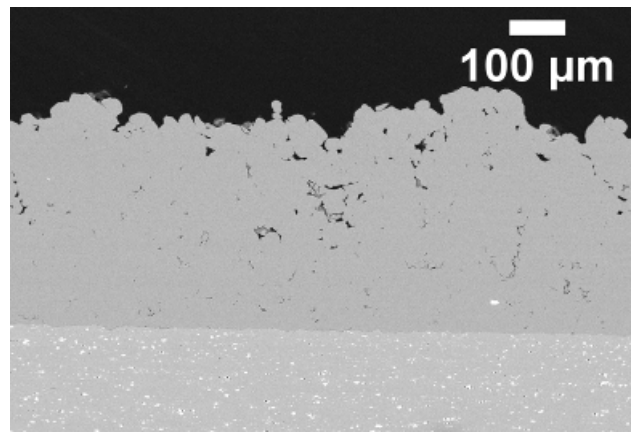

(a)

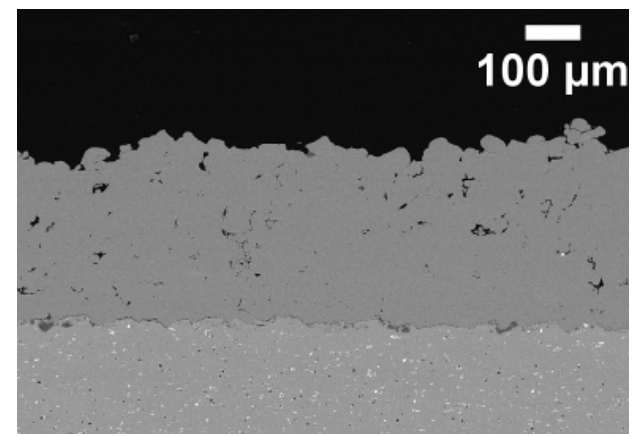

(c)

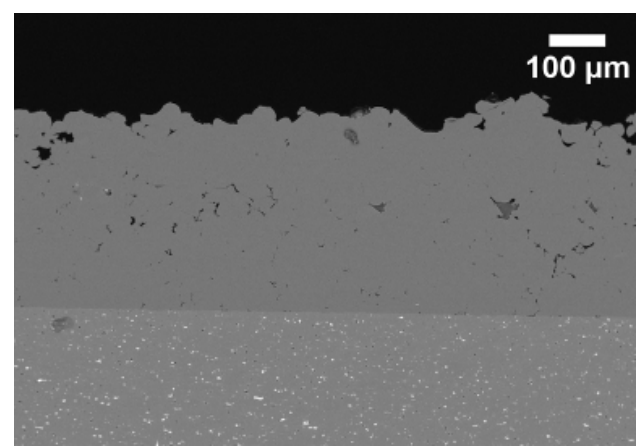

(e)

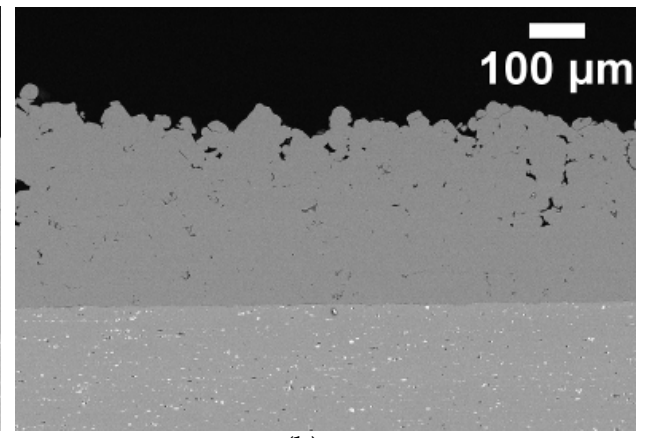

(b)

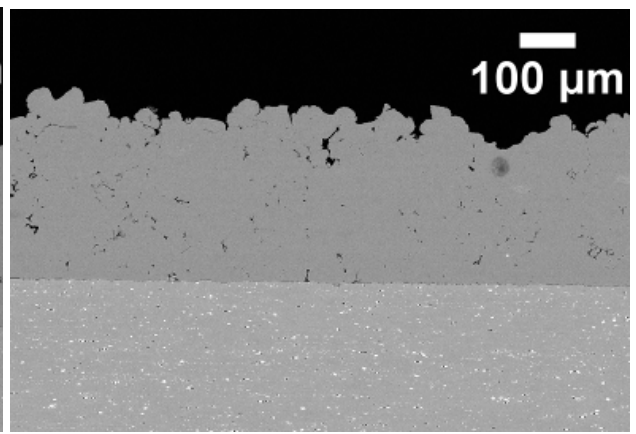

(d)

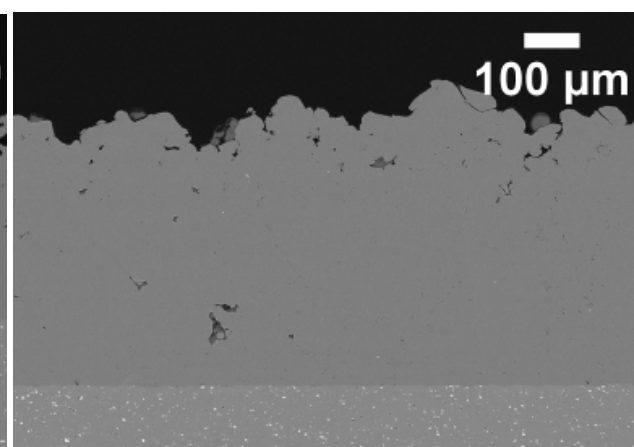

(f)

Fig. 13. SEM of cross-sections of cold-sprayed Al coatings formed onto (a) as-received, (b) mirror-polished substrate, (c) grit-blasted substrate, (d) laser irradiated substrate $\left(1.0 \mathrm{~J} . \mathrm{cm}^{-2}\right.$, $37.5 \mathrm{~Hz}),(\mathrm{e})$ laser irradiated substrate $\left(2.2 \mathrm{~J} . \mathrm{cm}^{-2}, 37.5 \mathrm{~Hz}\right)$, (f) laser irradiated substrate $(2.2$ J.cm-2, $150 \mathrm{~Hz})$ 
of coatings deposited on untreated and on laser ablated (2.2 J.cm-2, $37.5 \mathrm{~Hz})$ substrate is around $50 \mu \mathrm{m}$. One can conclude that this difference corresponds well to the difference of average coating thickness as shown in figure 13. The improved deposition efficiency with high fluence laser ablation is due essentially to the adhesion of a higher fraction of particles during the first pass as compare to other surface pre-treatment and laser ablation conditions. Nevertheless, it is clear that a large fraction of the impinging particles are not deposited during the first pass even at higher laser ablation fluence and so they should contribute to the surface modification as well.

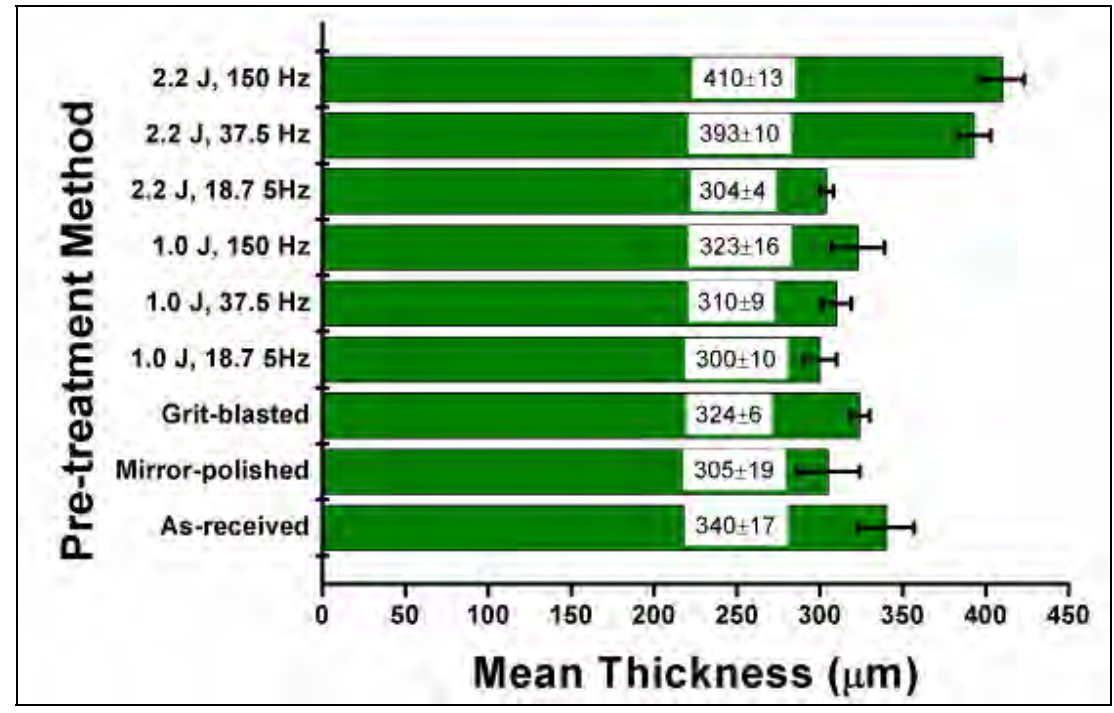

Fig. 14. Thickness of Al cold sprayed coatings for different pre-treatment methods

\subsubsection{Coating-substrate interface}

The percentage of cracked interfaces was determined by means of quantitative image analysis (Image $\left.{ }^{\circledR}(\operatorname{Ref} 47)\right)$. About $10 \mathrm{~mm}$ of interface was examined parallel to the spraying direction. The examined $10 \mathrm{~mm}$-region corresponds to about $60 \mathrm{SEM}$ images of high magnification $(\times 1000)$.

Representative interfaces between thick coating and the substrate are presented in figure 15. It was found that the grit blasting and polishing pre-treatment did not offer any reduction of cracks observed on the as-received substrates (figure 16). Surprisingly, the grit-blasting of the substrate contributed to the increase of the percentage of cracked interface (figure 15). Also, in the case of grit-blasted substrates, alumina particles entrapped onto the substrate were seen (figure 15c).

Conversely, Nd-YAG laser ablation promoted a better interface with much less interfacial cracks (figure 16). For the highest laser energy density $(2.2 \mathrm{~J} . \mathrm{cm}-2)$ and under the highest frequency $(150 \mathrm{~Hz})$, cracks could barely be found in direction perpendicular to spraying and did not appear at all in the parallel direction (Figure 16c). 


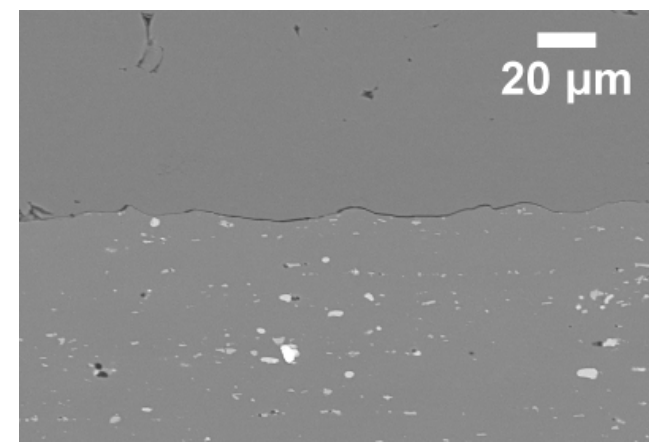

(a)

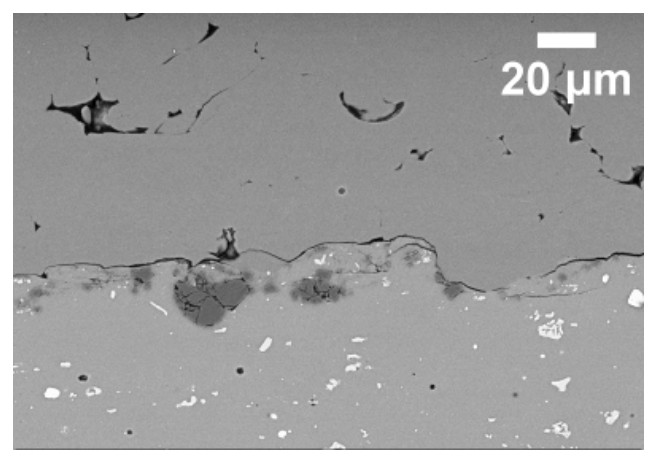

(c)

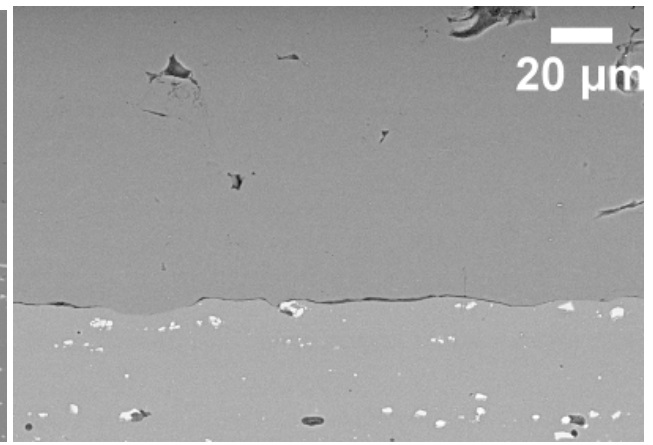

(b)

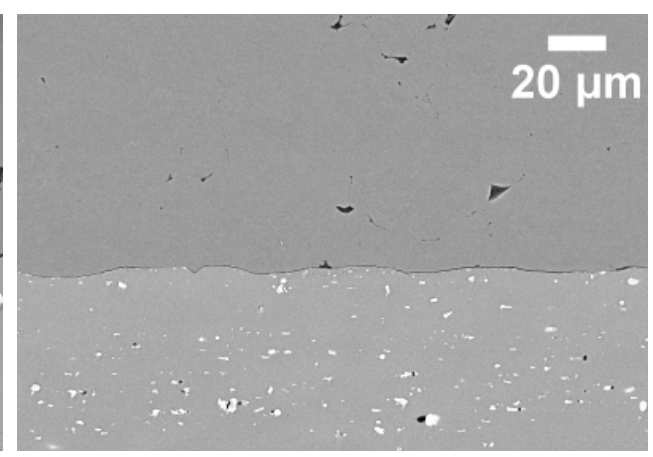

(d)

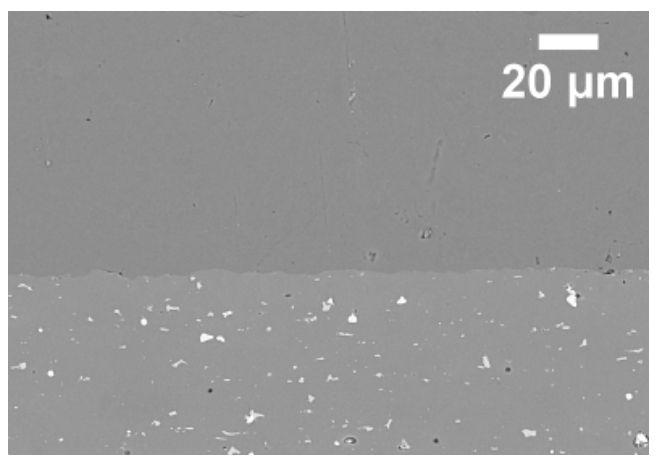

(e)

Fig. 15. SEM of cross-sections of cold-sprayed Al coatings formed onto (a) as-received substrate, (b) mirror-polished substrates, (c) grit-blasted substrate (d) laser irradiated substrate $\left(1.0 \mathrm{~J} . \mathrm{cm}^{-2}, 150 \mathrm{~Hz}\right)(\mathrm{e})$ laser irradiated substrate $\left(2.2 \mathrm{~J} . \mathrm{cm}^{-2}, 150 \mathrm{~Hz}\right)$.

The difference of the percentage of interfacial cracks between parallel and perpendicular is due to the difference in the size of the particle jet compared to the size of the laser spot (figure 11). In the perpendicular direction, fraction of sprayed particles impact on untreated areas and so these particles can present weaker adhesion (Christoulis et al., 2010). On the 
other hand, in the parallel direction, cold-sprayed particles always impact on laser pretreated areas, if the cross section metallographic sample is prepared properly, and thus along this direction a reduced percentage of interfacial cracks is observed.

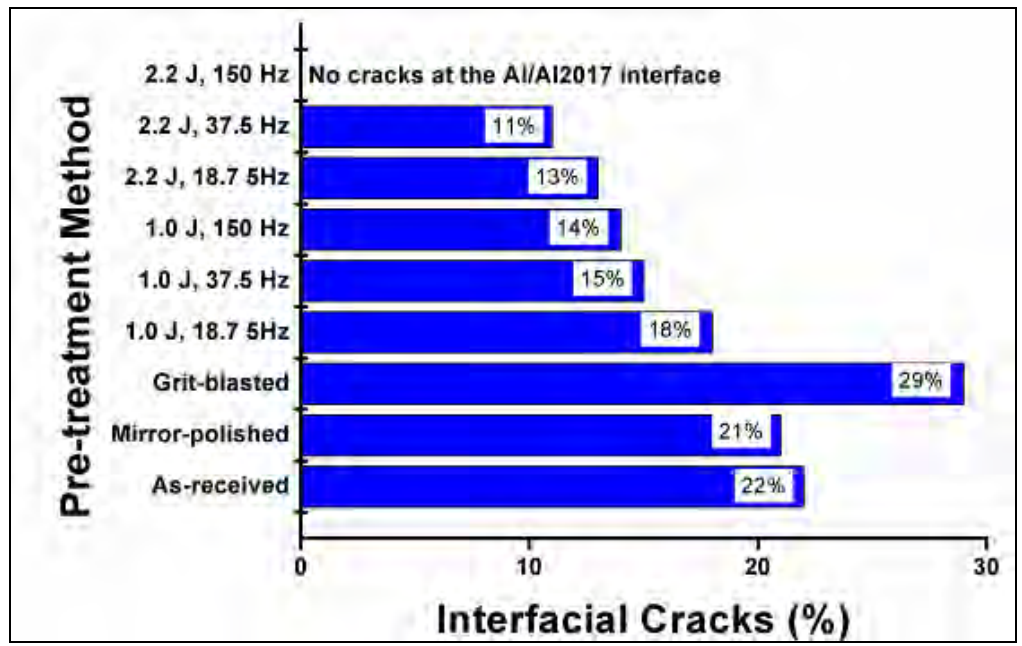

Fig. 16. Percentage of interfacial cracks between cold-sprayed Al coatings and substrates.

\subsubsection{TEM observations}

Thin foils of Al-coatings were prepared by FIB and they were examined with TEM.

A typical oxide layer of about $100 \mathrm{~nm}$ in thickness could be observed at the coating-substrate interface in cold-sprayed "as-received" Al 2017 (figure 17). The EDX indicates that this oxide layer is in fact divided in two regions of distinct $\mathrm{Al} / \mathrm{O}$ ratio. (in gray in figure 17a). The layer at the substrate side has the stoichiometry of alumina indicating that it is the native oxide while the other one at the coating side is richer in oxygen ( 35\%wt $\mathrm{Al}, 65 \% \mathrm{wt} \mathrm{O})$

TEM analysis indicates that the oxide layer oxide at the coating side is amorphous since the grey contrast of this oxide layer was constant. Furthermore, EFTEM (Energy Filtered Transmission Electron Microscope) with GIF (Gatan Image Filter) image recorded on the low loss region (Plasmon) of the EELS spectrum highlights this interfacial layer, which is characteristic of amorphous structure (Gertsman et al., 2005).

The transformation of the native alumina oxide to an amorphous $\mathrm{Al}$ oxide could be the results of extensive peening by the impinging particles (similar to what is observed in mechanical milling for example (Gaffet et al., 1997; Li et al., 2009). Indeed, it was reported that amorphyzation can occur during cold spraying (Xiong et al., 2008). It is interesting to note that most of the cracks observed at the interface were propagated in between the two oxides.

In contrast, for laser-processed $\mathrm{Al} 2017$, no oxygen could be detected at the interface (figure 18) neither on STEM images nor by EDX profile. This profile was obtained with a probe size of $1 \mathrm{~nm}$ (enlarged to $3 \mathrm{~nm}$ at the exit side of the thin foil), $10 \mathrm{~nm}$ between the consecutive analysis spots, and a limit of detection of $1 \% \mathrm{wt}$ for $\mathrm{O}$. It can therefore be inferred that the 
native layer was removed by the laser treatment, and if an oxide thinner layer was formed prior to the particle reached the substrate, the thickness of this layer would not exceed a few nanometers

\subsubsection{LASAtesting}

Laser shock adhesion testing was performed both on coating formed onto as-received substrates and onto laser irradiated substrates $\left(2.2 \mathrm{~J} . \mathrm{cm}^{-2}, 150 \mathrm{~Hz}\right)$.

The lower adhesion of Al-coatings onto as-received substrates was confirmed by LASAT experiments. Coatings were totally de-bonded with the lower laser energy $\left(1.7 \mathrm{GW} . \mathrm{cm}^{-2}\right)$ (figure 19a). These results are confirmed also by VISAR signals (see figure 20). The velocity peaks corresponded to shock wave interaction with the coating surface. For both LASAT energies, the absence of negative peaks corresponds to the damage of coating-substrate interface (Barradas et al., 2005).

Onto pre-treated substrates $\left(2.2 \mathrm{~J} . \mathrm{cm}^{-2}, 150 \mathrm{~Hz}\right)$, cold-sprayed aluminum coatings presented higher adhesion. When low laser energy $\left(1.7 \mathrm{GW} . \mathrm{cm}^{-2}\right.$, figure $\left.19 \mathrm{~b}\right)$ was used, the coating remained adherent. The increase of LASAT energy $\left(2.6 \mathrm{GW} . \mathrm{cm}^{-2}\right.$, Figure 19c) provoked the interlamelar cracking of the Al-coatings. This revealed that the cohesion of the coatings (bonding of cold-sprayed Al-Al) was weaker compared with the coating-substrate adhesion. Similar phenomenon has been found for cold-sprayed copper on AISI 2017 substrate (Barradas et al., 2005).

At higher LASAT laser energy $\left(4.3 \mathrm{GW} . \mathrm{cm}^{-2}\right)$ the coating was de-bonded from the laser pretreated substrate, (figure 19c). However, few particles still remained bonded reveling the high achieved adhesion strength.

For laser pre-treated substrates the VISAR results are well segregated (figure 20). For low LASAT energy (2.6 GW. $\mathrm{cm}^{-2}$, black line) the aluminum surface velocity showed negative values after the first positive peak. The positive velocity peaks correspond to shock wave interaction with the coating surface while the negative peaks correspond to tensile stresses reaching the substrate surface (Barradas et al., 2005). The tensile stresses were those generated at the aluminum surface, after their propagation through the whole sample. On the other hand for high LASAT energy $\left(4.6 \mathrm{GW} . \mathrm{cm}^{-2}\right)$ only a positive peak was detected since the tensile wave reflected on the thus-created cracks and the surface coating velocity did not show negative values. The tensile stress at the interface, 022 , was calculated from modeling/numerical simulation of $1 \mathrm{D}$ and $2 \mathrm{D}$ shock wave effects within the coatingsubstrate system and averaged over the whole laser spot (Boustie et al., 2000). Bonding strength value could therefore be determined from "post-mortem" observation of interfacial cross-sections and study of VISAR velocity profiles (figure 20) during the test, since both show when the coating de-bonds (figure 20). The bond strength was found to be above 629 MPa but below $681 \mathrm{MPa}$ for laser-ablated Al 2017 compared to below (one may assume much below) $562 \mathrm{MPa}$ for as-received $\mathrm{Al}$ 2017. These bond strength values are significantly higher than what is typically reported for pull-off ASTM C633 testing which lies in the 10-80 MPa range (Price et al., 2006; Stoltenhoff et al., 2006; Shin et al., 2008; Triantou et al., 2008), while for some conditions of aluminum coating applied on Aluminum 7075 alloy substrate the failure mode was in the glue at over $60 \mathrm{MPa}$ (Irissou et al., 2007). 


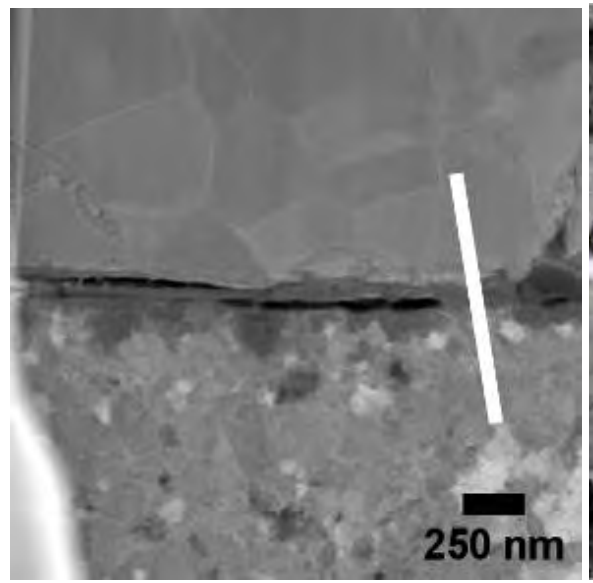

(a)

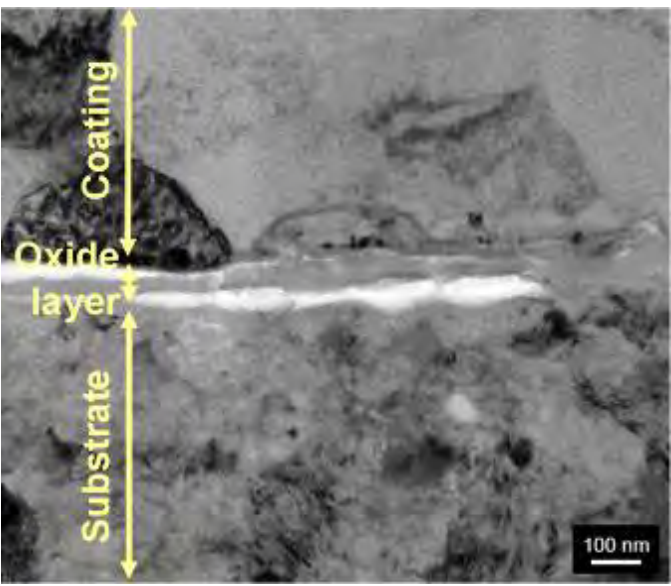

(b)

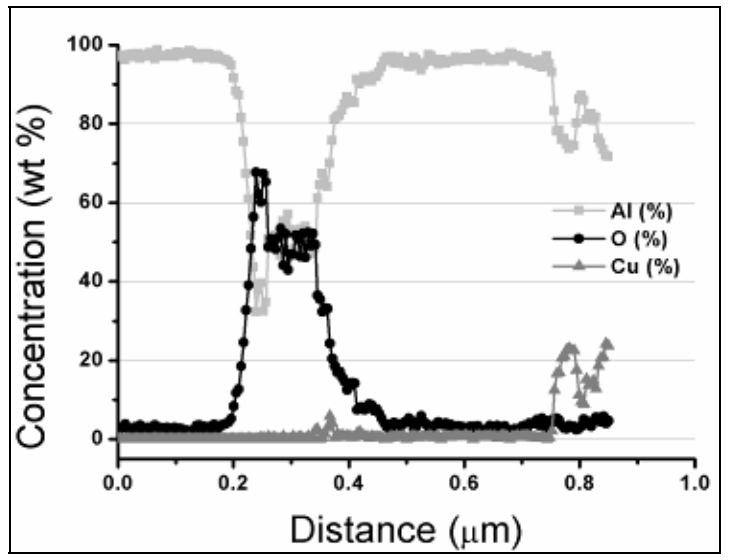

(c)

Fig. 17. TEM pictures of cold-sprayed Al on as-received AISI 2017 substrate (a) Bright Field (BF) image, (b) HAADF (High Angle Annular Dark Field) image, (c) EDX profiles along the white line. 


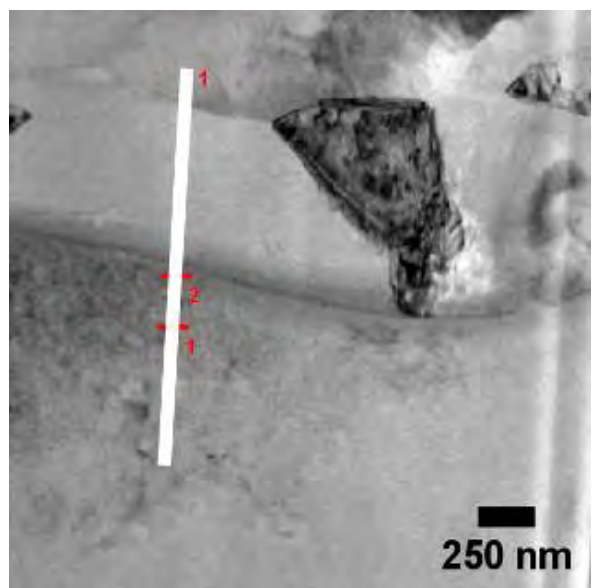

(a)

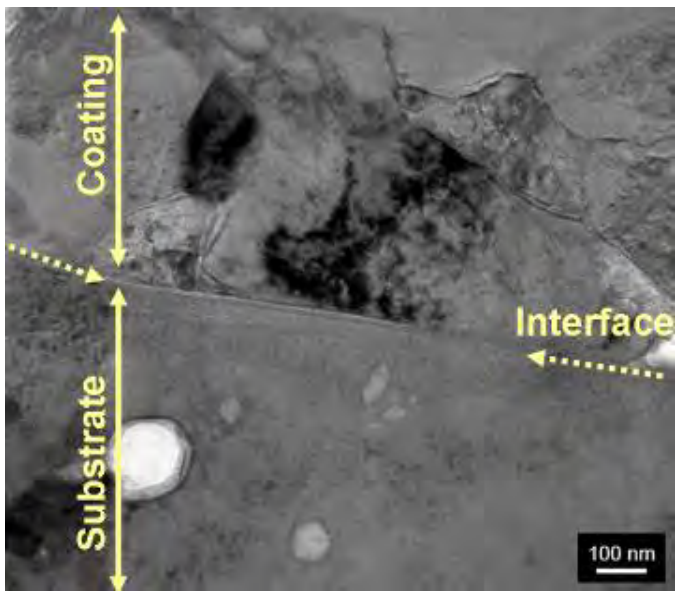

(b)

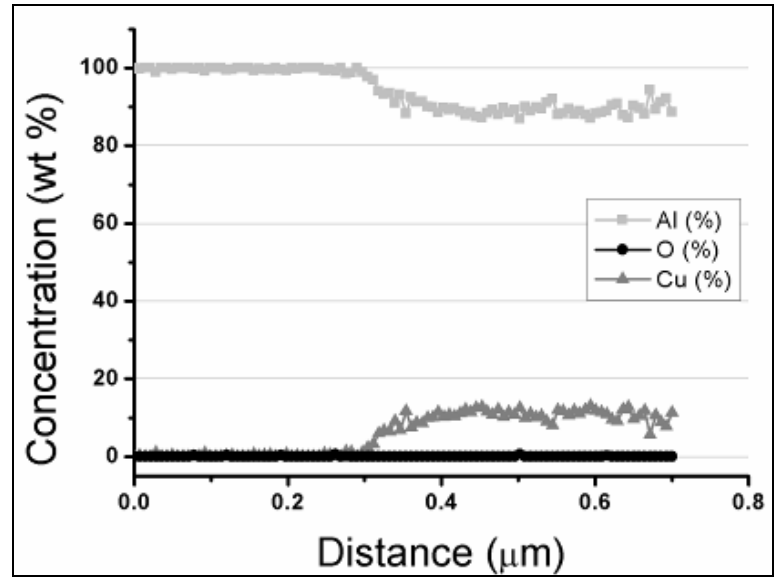

(c)

Fig. 18. TEM pictures of cold-sprayed Al on laser pre-treated (2.2 J.cm-2, $150 \mathrm{~Hz})$ AISI 2017 substrate (a)Bright Field (BF) image, (b) HAADF (High Angle Annular Dark Field) image, (c) EDX profiles along the white line 


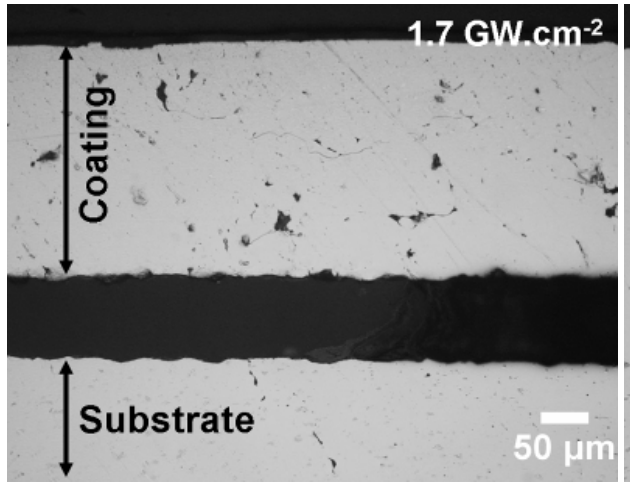

(a)

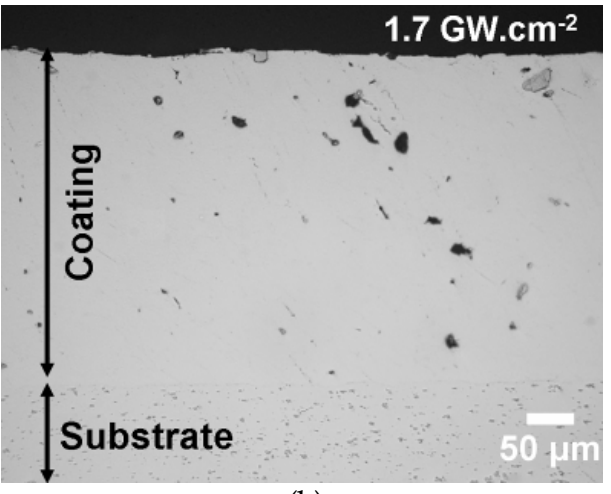

(b)

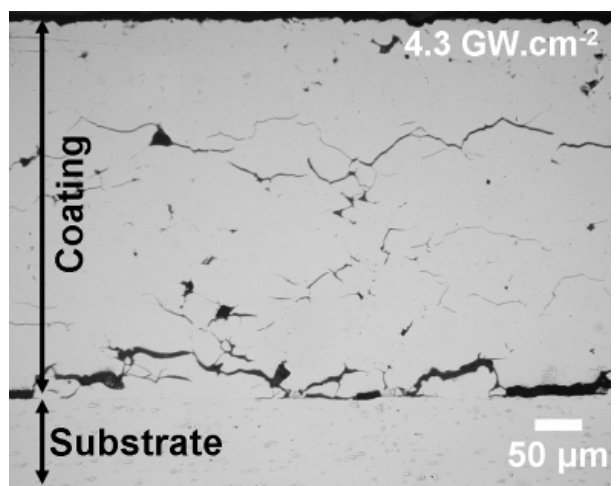

(c)

Fig. 19. Cross-section optical image of LASATested interface of cold-sprayed Al onto (a) asreceived substrate when the applied LASAT energy was $1.7 \mathrm{GW} . \mathrm{cm}^{-2}(\mathrm{~b})$ laser pre-treated (PROTAL 2.2 J.cm-2) substrate when the applied LASAT energy was $1.7 \mathrm{GW} . \mathrm{cm}^{-2}$ (c) laser pre-

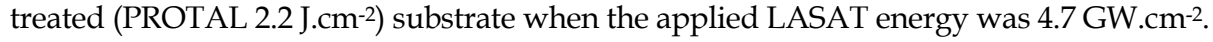

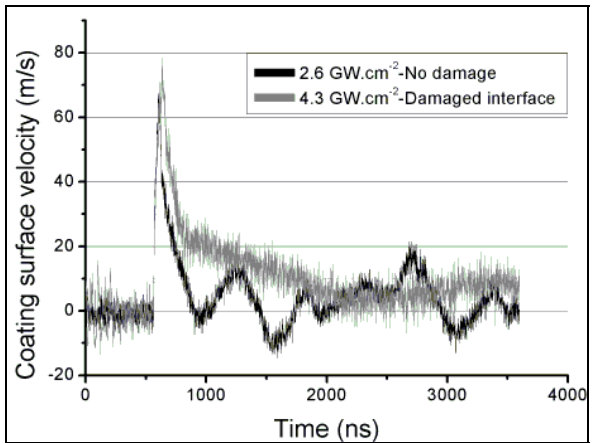

(a)

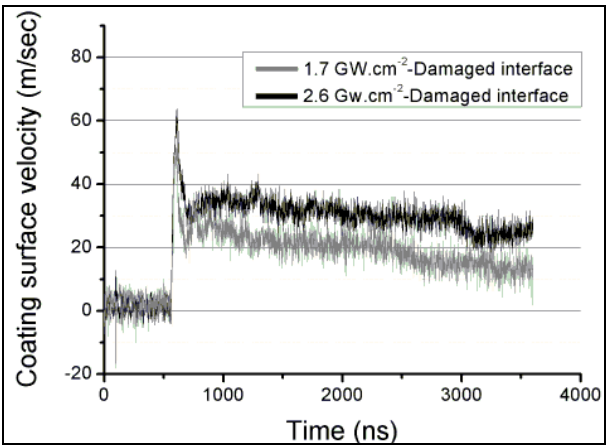

(b)

Fig. 20. Velocity profiles of cold-sprayed Al surface on (a) as- received AISI 2017 substrate (b) laser pre-treated $\left(2.2 \mathrm{~J} . \mathrm{cm}^{-2}\right)$ substrate AISI 2017 


\subsection{Ni-based LACS Coatings}

\subsubsection{Materials}

The feedstock powder was commercial Ni-20Cr (Höganäs, 1616-09/PS) of spherical morphology (figure 21a) and with particle size ranging from 20-53 $\mu \mathrm{m}$ (figure $21 \mathrm{~b}$ ). The powders microhardness was measured at $192 \pm 15 \mathrm{HV}_{0.05}$. The powder was sprayed onto Inconel alloy 718 substrate.

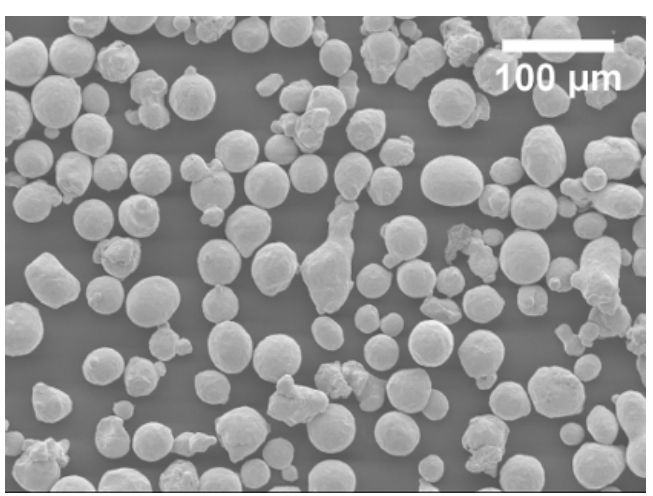

(a)

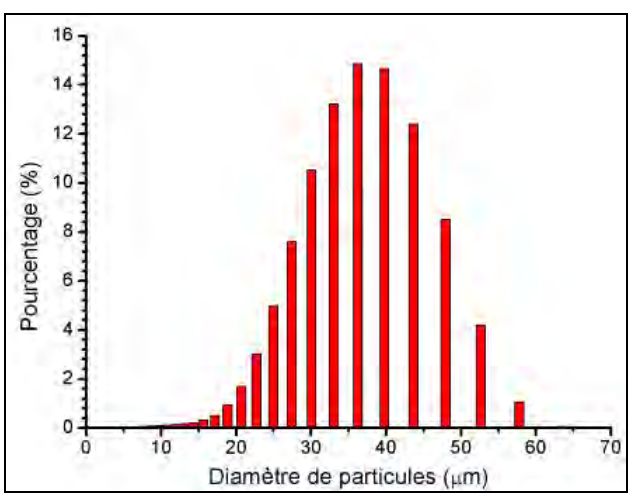

(b)

Fig. 21. SEM of Ni-20Cr powder (Höganäs, 1616-09/PS) and (b) Particle distribution by laser analysis.

\subsubsection{Laser irradiation effects}

Observations of the as-received substrates revealed a superficial "cellular" structure (Figure 22). The modifications induced on the substrates by the nano-pulsed Nd-YAG laser, are presented in Figure 22 as function of the laser energy and frequency. For low laser energy $\left(1.0 \mathrm{~J} . \mathrm{cm}^{-2}\right)$, at the lowest frequency $(18.75 \mathrm{~Hz})$ the laser provoked the partially removal of the "cellular" structure (some cells are still observed) and a new structure full of small craters was revealed. It seems that the laser impulses caused the local fusion of the substrate. The craters on the surface can be correlated either with the surface defects, such as micro-inclusions and small visible scratches prior to irradiation either with the existence of precipitated phases as it has been found in the case of al-alloy (Costil et al., 2004), but further studies should be done in order to verify this assumption. The gradual increase of the frequency from to 18.75 to $150 \mathrm{~Hz}$ resulted in the complete ablation of the initial "cellular" structure.

The increase of the laser energy to $2.2{\mathrm{~J} . \mathrm{cm}^{-2}}^{2}$ induced more intensive melting of the substrate surface. The craters were reduced and it seems that the more intensive fusion led to their coverage. Increasing the frequency, which corresponds to the increase of overlapping, smoothened the substrate surface where neither the initial "cells" either their borders can be seen. 


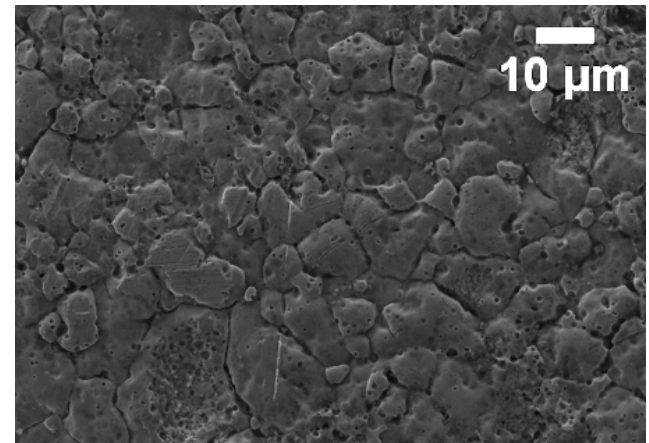

(a)

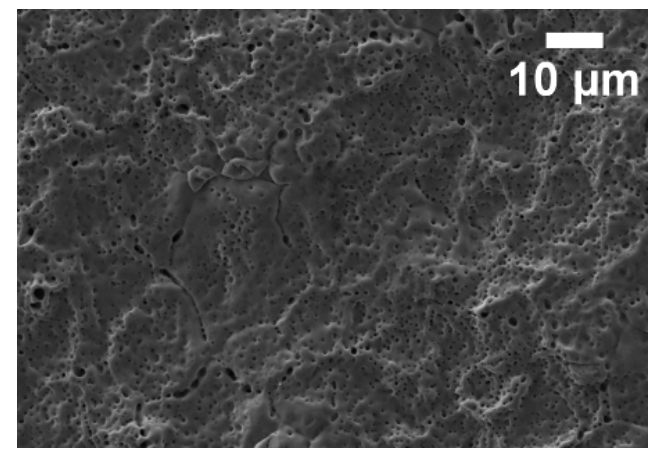

(c)

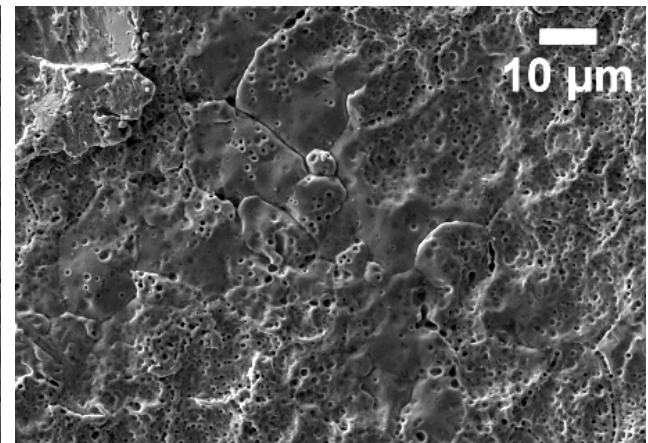

(b)

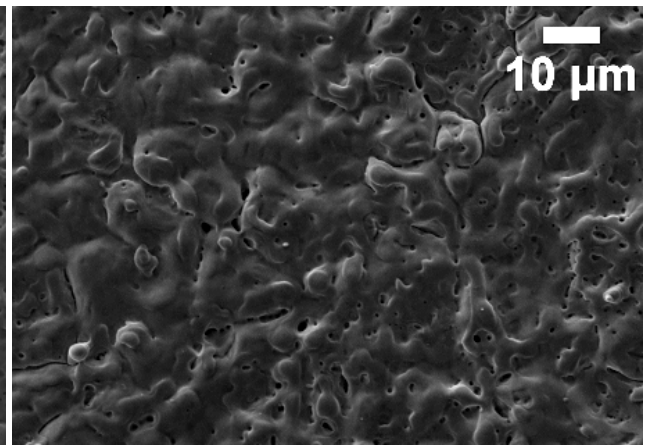

(d)

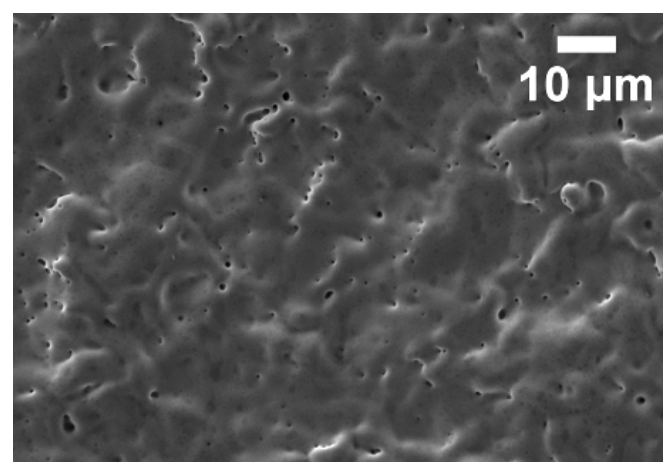

(e)

Fig. 22. SEM top view of Inconel 718 substrate surfaces: (a) un-treated and Nd-YAG laser

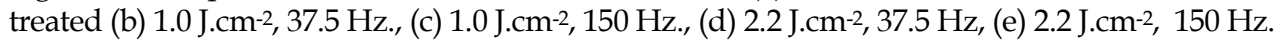

\subsubsection{Formation of thick $\mathrm{Ni}-20 \mathrm{Cr}$ coatings}

The cross-sections of the coatings were investigated by Scanning Electron Microscopy (SEM, LEO 450VP). Conventional image analysis software (Image $\left.{ }^{\circledR}\right)$ was used to calculate the mean thickness. The mean thickness of the coatings was calculated by observing 12 SEM 
images in standard magnification of $\times 200$ (figure 23). The 12 images correspond to about 6 $\mathrm{mm}$ length. The mean thickness of the coatings for the different pre-treatment methods of the substrate is presented in figure 24 .

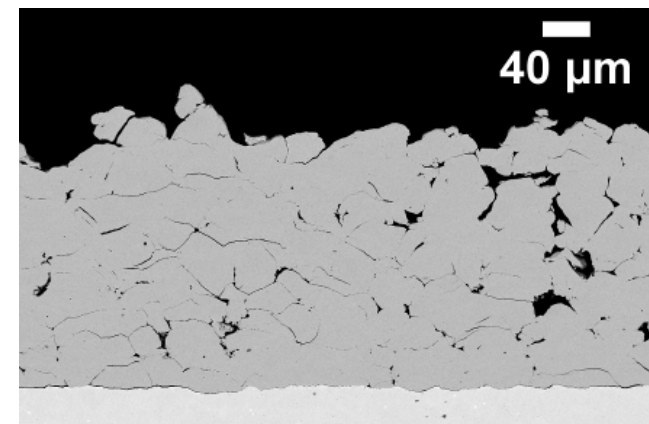

(a)

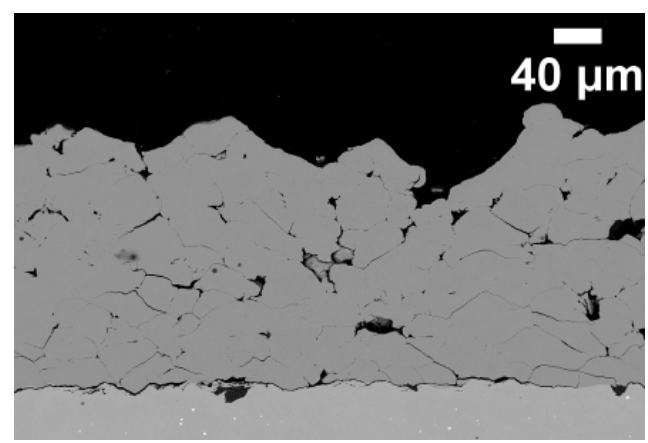

(c)

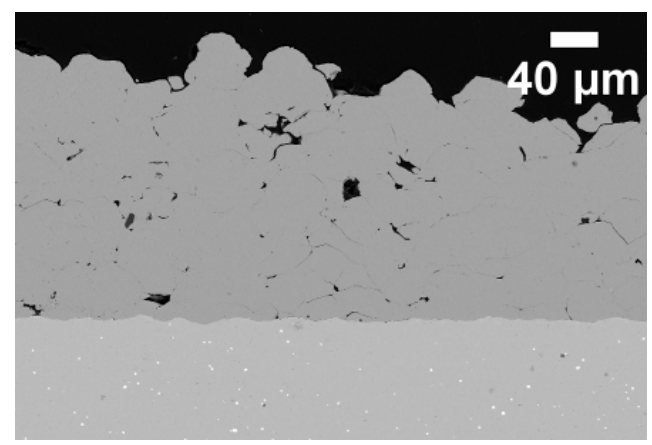

(e)

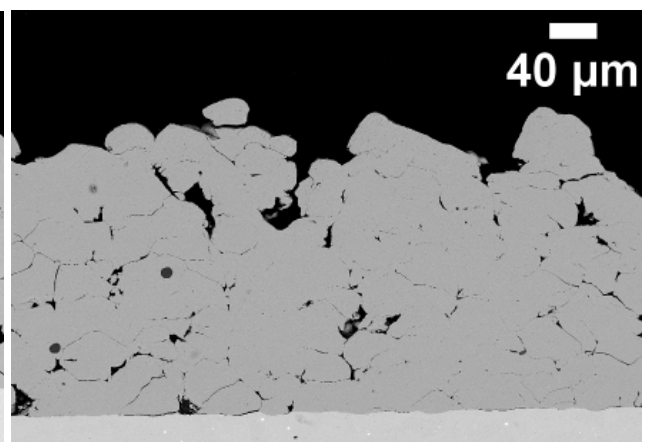

(b)

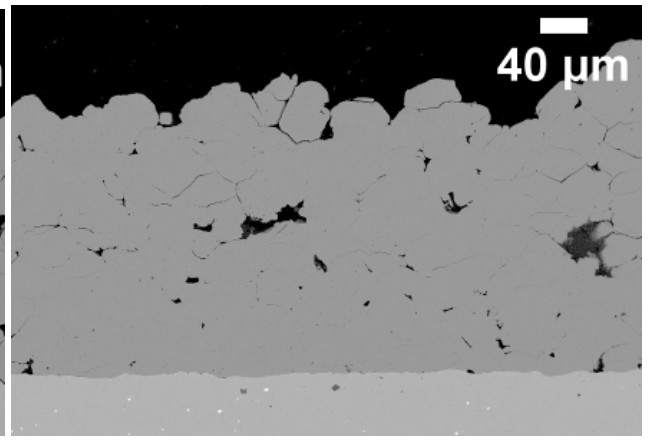

(d)

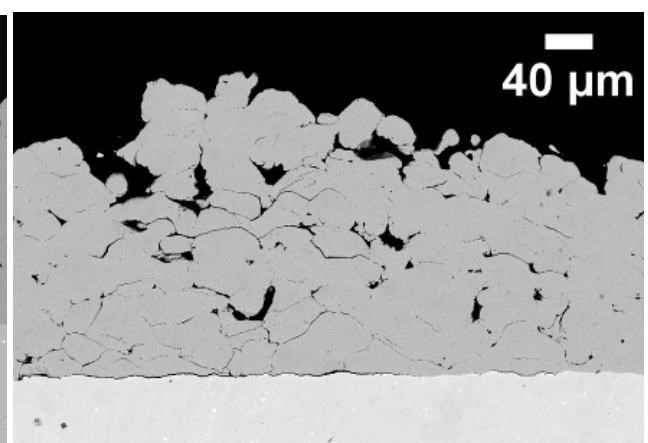

(f)

Fig. 23. SEM of cross-sections of Ni-20Cr cold-sprayed coatings formed onto (a) as-received substrate, (b) mirror-polished substrate, (c) grit-blasted substrate, (d) laser irradiated substrate $\left(1.0 \mathrm{~J} . \mathrm{cm}^{-2}, 37.5 \mathrm{~Hz}\right),(\mathrm{e})$ laser irradiated substrate $\left(2.2 \mathrm{~J} . \mathrm{cm}^{-2}, 37.5 \mathrm{~Hz}\right)$, (f) laser irradiated substrate $\left(2.2 \mathrm{~J} . \mathrm{cm}^{-2}, 150 \mathrm{~Hz}\right)$ 


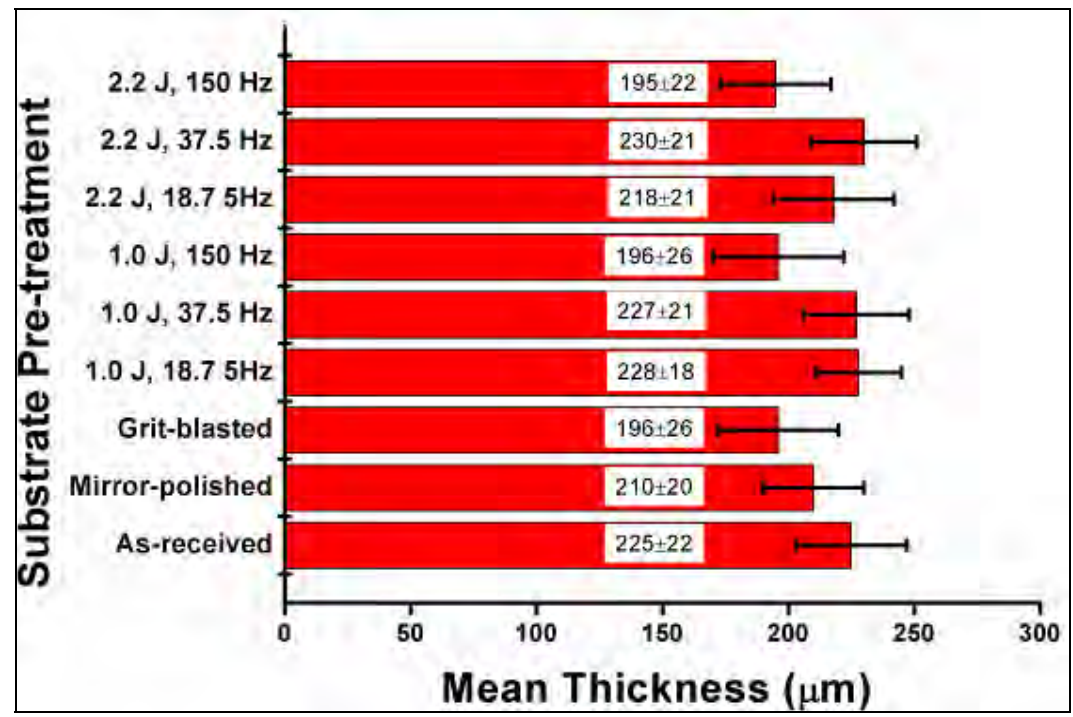

Fig. 24. Thickness of Ni-20Cr cold sprayed coatings for different pre-treatment methods

\subsubsection{Coating-substrate interface}

The percentage of cracked interfaces was determined by means of quantitative image analysis (Image $\left.{ }^{\circledR}\right)$. About $10 \mathrm{~mm}$ of interface was examined parallel to the spraying direction. The examined $10 \mathrm{~mm}$-region corresponds to about $30 \mathrm{SEM}$ images of high magnification $(\times 500)$.

Representative interfaces between thick coating and the substrate are presented in figure 25 . It was found that the grit blasting and polishing pre-treatment did not offer any reduction of cracks observed on the as-received substrates (figure 16). As it was found in the case of coldsprayed Al coatings onto AISI 2017 substrates (figures 15 and 16) the grit-blasting of the substrate contributed to the increase of the percentage of cracked interface (figure 26). Also, in the case of grit-blasted substrates, alumina particles entrapped onto the substrate were seen (figure $25 \mathrm{c}$ ).

On the other hand, Nd-YAG laser ablation promoted a better interface with much less interfacial cracks (figure 26). The optimum ablation conditions for LACSsprayed Ni-20Cr coatings were found to be: laser energy of $2.2 \mathrm{~J}_{\mathrm{cm}} \mathrm{cm}^{-2}$ and laser frequency of $37.5 \mathrm{~Hz}$. Under these conditions the percentage of interfacial cracks between $\mathrm{Ni}-20 \mathrm{Cr}$ coatings and Inconel 718 substrate was decrease at the lowest value of $7.8 \%$ (figure 26). 


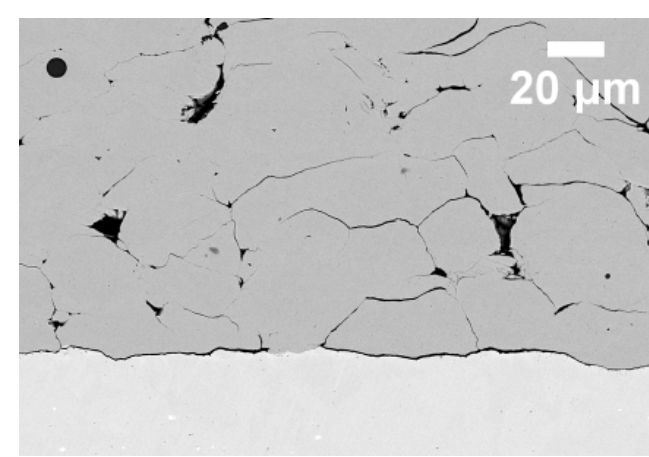

(a)

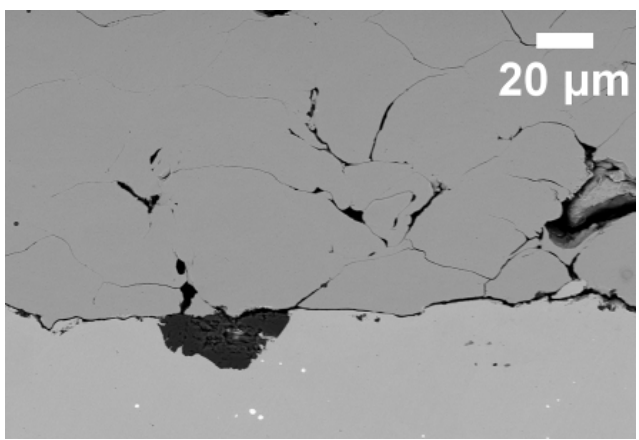

(c)

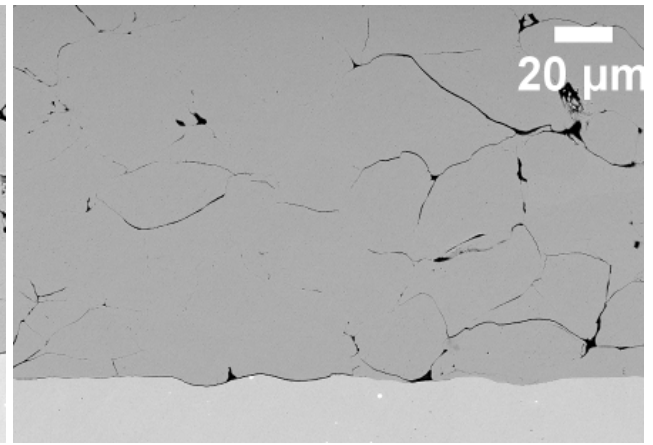

(b)

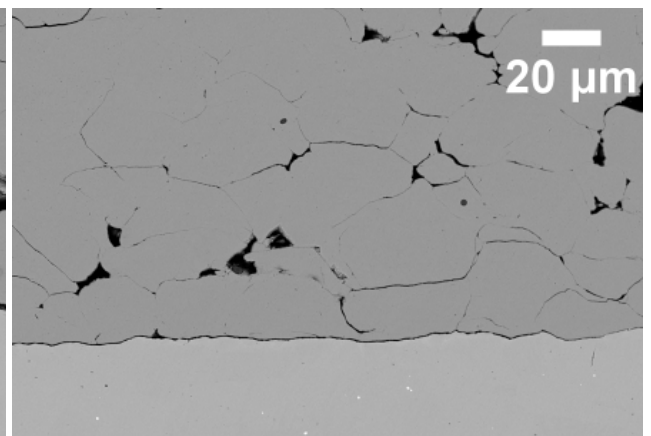

(d)

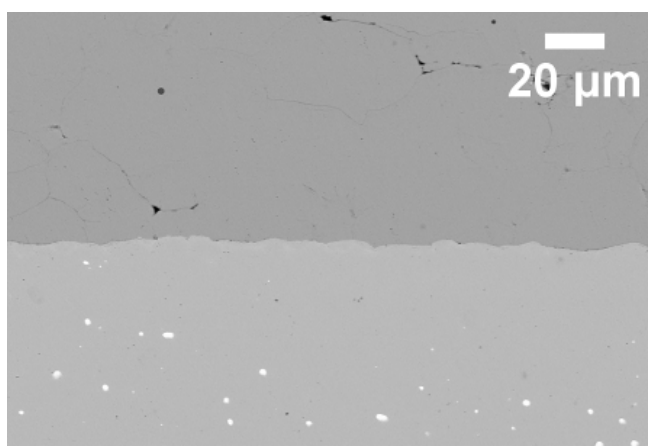

(e)

Fig. 25. SEM of cross-sections of cold-sprayed Al coatings formed onto (a) as-received substrate, (b) mirror-polished substrates, (c) grit-blasted substrate (d) laser irradiated substrate $\left(1.0 \mathrm{~J} . \mathrm{cm}^{-2}, 18.75 \mathrm{~Hz}\right)(\mathrm{e})$ laser irradiated substrate $\left(2.2 \mathrm{~J} . \mathrm{cm}^{-2}, 37.5 \mathrm{~Hz}\right)$.

The further increase of the laser frequency at $150 \mathrm{~Hz}$ for the highest laser energy $\left(2.2 \mathrm{~J} . \mathrm{cm}^{-2}\right)$ provoked a significant increase of the interfacial cracks (50\%, figure 26). Based on SEM top view of Inconel 718 substrate surfaces (figure 22), it is assumed that the increase of the laser frequency resulted in extensive melting of the substrate, which in turn could 
increase the pores and the cracks due the change of the interaction between the sprayed particles and the substrate.

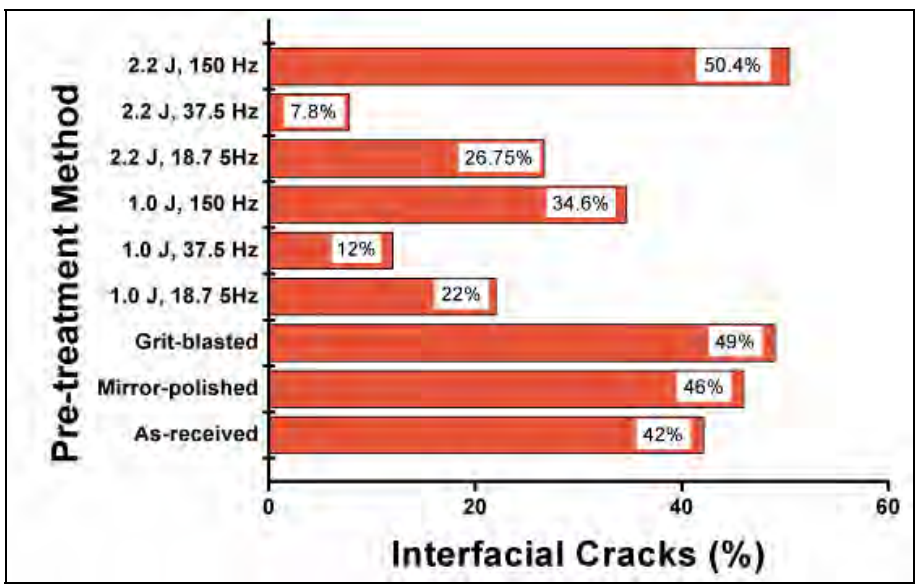

Fig. 26. Percentage of interfacial cracks between cold-sprayed Al coatings and substrates.

\section{Conclusion}

The use of the cold spray system for the formation of the coatings has the potential to overcome all the drawbacks which are induced by the conventional thermal spray technologies. Moreover, the Laser Assisted Cold Spray is a novel process, for the pretreatment of the substrate and the coatings build-up, which may lead to the production of advanced coatings of high adhesion and cohesion strength. Nowadays, the adhesion of cold sprayed coatings is improved by using environmental unfriendly pretreatment techniques (grit-blasting and chemical solvents) while the cohesion is improved by thermal post-treatments which can eliminate one of the main advantages of cold spray technology; the formation of oxide-free coatings. The conventional techniques for the improvement of adhesion and cohesion techniques are two-step process while LACS permits the creation of dense novel coatings of high adhesion and cohesion strength in one-step process.

Two different coating systems (Al-based coatings and Ni-based coatings) were studied by using a LACS system where the cold spray gun was coupled with a nano-pulsed Nd-YAG laser head. It was found that at optimized laser ablation conditions, coatings of higher thickness are formed. Also, under the optimized laser condition the interfacial cracks between the deposited coatings and the ablated substrates were reduced dramatically. For both Al-based and Ni-based coatings, cross section micrographs revealed that of a significant interface (coatings-substrate) length are cracked on samples prepared with conventional methods (grit blasting and polishing) polished or wrough substrates.

For Ni-20Cr coatings onto Inconel 718 substrate the optimized laser conditions found to be: 2.2 J.cm-2 Laser energy density and $37.5 \mathrm{~Hz}$ Laser frequency.

In the case of al-based coatings onto AISI 2017 substrates, the optimized laser conditions were found to be: $2.2 \mathrm{~J} . \mathrm{cm}-2$ Laser energy density and $37.5 \mathrm{~Hz}$ Laser frequency. TEM studies 
on the al-based coatings revealed that an amorphous aluminium oxide phase was created at the interface on the coating side while an alumina layer is still present on the substrate side. Most of the cracks observed at the interface were propagated in between the two oxides. The adhesive strength between the aluminium coating and the amorphous aluminium oxide layer thus seems higher than that between the two oxide layers. Pulsed laser ablation at optimized conditions $\left(2{\mathrm{~J} . \mathrm{cm}^{-2}}^{2}, 37.5 \mathrm{~Hz}\right)$ eliminated the native oxide at the substrate surface, leading to the formation of al-coatings with the highest level of adhesion strength for the examined conditions.

The adhesion of LACSpraeyd al-based coatings was measured by employing a Nd-YAG laser based system (LASAT). The bond strength of Al cold-sprayed coating was numerically calculated from LASAT measurements and it was found to lie in between 629 and $681 \mathrm{MPa}$ for samples prepared on laser pre-treated substrates $(2.2 \mathrm{~J} . \mathrm{cm}-2,150 \mathrm{~Hz})$ in between and below $562 \mathrm{MPa}$ on as-received substrate. The experimental results shown that LASATesting is a powerful tool for studying local adhesion of coatings and for determining the influence of metallurgical and morphological interface features on adhesion.

\section{Outlook}

Laser Assisted Cold Spray process can shed light on an open query of cold spray technology. The presence of local transient melting at the interface of substrate and particles, and its contribution to the bonding of cold-sprayed particles has not been clarified yet. Experimental studies show evidence of local fusion at the substrate-particle interface (Barradas et al., 2007; Guetta et al., 2009) as well as interlamellar local melting (Li et al., 2007). In these cases, an increase of adhesion of cold sprayed coatings is observed due to the presence of molten phases (Barradas et al., 2007). On the other hand, other experimental results (Ref 12) and numerical simulations (Bae et al., 2009) indicate that, during the creation of cold-sprayed coating, melting cannot occur at the particle-substrate interface. While, in the case of cold sprayed aluminum onto tin substrate, the rebound of the particles is associated with substrate local fusion (Zhang et al., 2003). The presence or the absence of local melting seems to depend on the materials used and experimental conditions. It is therefore possible that local fusion can exist only under certain conditions (materials, gas and temperatures etc). The Laser Assisted Cold Spray can enlighten the role of the local melting at the interface between substrate and the sprayed particles. The laser ablation energy of the Nd-YAG laser should be adjusted to the appropriate level to provoke the melting of the substrate surface. These experiments will answer to an open fundamental query of cold spray technology: does the melting of the substrate enhance the adhesion strength of cold sprayed coating or not?

Furthermore, the Nd-YaG laser should be used, also, during coatings' build-up to enhance coatings' cohesion. The weak cohesion of cold-sprayed particles is one of the disadvantages of the cold spray process. The weak cohesion decreases coatings' properties and limits further industrial applications of cold spray technology. Presently, in order to improve the cohesion of cold-sprayed coatings, thermal post-treatment techniques are used (Hall et al., 2006; Makinen et al., 2007; Spencer et al., 2009). After the deposition of the cold sprayed coating, a thermal treatment follows. This two-step process can be replaced by a single step process: the coupling of cold-spraying with the Nd-YaG laser; thus cold-sprayed coatings of both high adhesion and cohesion strength will be created. 
Laser-Assisted Cold Spray, should be coupled also with other type of laser which are suitable to create a particular structure on the substrate (Knapp et al., 2011). Among the various laser surface processes, laser structuring is currently one of the most developed and promising. Beyond the mere application to engraving, laser structuring of a substrate (whatever the type of material) is expected to improve bond-strength when coated with a layer. The latter can be obtained using cold spray in particular.

\section{Acknowledgements}

The authors would like to thank Mr. B. Harvey and Mr. M. Lamontagne both of Industrial Material Institute (Boucherville, Canada) for Cold-spray and PROTAL $\AA$ process, respectively. Professor K. Ogawa, Associate Professor Y. Ichikawa, Mr. K. Sagakuchi and Dr. T. Miyazaki, of Tohoku University (Sendai, Japan) are acknowledged for FIB cuttings. The current project was carried out in the framework of the Cold-spray Club (www.mat.ensmp.fr/clubcoldspray).

\section{References}

Ajdelsztajn L., Zuniga A., Jodoin B., Lavernia E.J. (2006). Cold Gas Dynamic Spraying of a High Temperature Al Alloy, Surface \& Coatings Technology, 2006, Vol. 201, pp. 2109211.

Araujo P., Chicot D., Staia M., Lesage J. (2005). Residual stresses and adhesion of thermal spray coatings, Surface Engineering, Vol. 21, No. 1, pp. 35-40

Arrigoni M., Barradas S., Braccini M., Dupeux M., Jeandin M., Boustie M., Bolis C., Berthe L. (2006). A comparative study of three adhesion tests (EN 582, similar to ASTM C633, LASAT, bulge and blister test) performed on plasma sprayed copper deposited on aluminium 2017 substrates, Journal of Adhesion Science and Technology, Vol. 20, No. 5, pp. 471-487

Bae G., Kang K., Na H., Lee C., Kim H.J. (2009). Thermally Enhanced Kinetic Sprayed Titanium Coating: Microstructure and Property Improvement for Potential Applications, Proceedings of the Expanding Thermal Spray Performance to New Markets and Applications, ISBN-13: 978-1-61503-004-0, Las Vegas, United States of America, May, 2009

Bahbou M.F., Nylen P., Wigren J. (2004). Effect of Grit Blasting and Spraying Angle on the Adhesion Strength of a Plasma-Sprayed Coating, Journal of Thermal Spray Technology, Vol. 6, No. 2, pp. 508-514.

Bala N., Singh H., Prakash S. (2010). High Temperature Corrosion Behavior of Cold Spray $\mathrm{Ni}-20 \mathrm{Cr}$ Coating on Boiler Steel in Molten Salt Environment at $900^{\circ} \mathrm{C}$, Journal of Thermal Spray Technology, Vol. 19, No. 1-2, pp. 110-118

Barbezat G. (2005). Advanced thermal spray technology and coating for lightweight engine blocks for the automotive industry, Surface $\mathcal{E}$ Coatings Technology, Vol. 200, pp.1990 $-1993$

Barbezat G. (2006). Application of thermal spraying in the automobile industry, Surface $\mathcal{E}$ Coatings Technology, Vol. 201, pp. 2028-2031

Barradas S., Jeandin M., Bolis C., Berthe L., Arrigoni M., Boustie M., Barbezat G. (2004) Study of Adhesion of PROTAL® Copper Coating of Al 2017 Using the Laser Shock Adhesion Test (LASAT), Journal of Materials Science, Vol. 39, pp 2707-2716 
Barradas S., Molins R., Jeandin M., Arrigoni M., Boustie M., Bolis C., Berthe L., Ducos M. (2005). Application of laser shock adhesion testing to the study of the interlamellar strength and coating substrate adhesion in cold sprayed copper coating of aluminum, Surface \& Coatings Technology, Vol. 197,pp. 18-27

Barradas S., Guipont V., Molins R., Jeandin M., Arrigoni M., Boustie M., Bolis C., Berthe L., Ducos M. (2007). Laser Shock Flier Impact Simulation of Particle-Substrate Interactions in Cold Spray, Journal of Thermal Spray Technology, Vol. 16, No. 4, pp. 548-556

Bobzin K., Schlafer T., Warda T., Bruhl M. (2010). Thermally Sprayed Oxidation Protection Coatings for $\mathrm{y}$-TiAl Substrates, 2010, Proceedings of Thermal Spray: Global Solutions for Future Application, ISBN 978-3-87155-590-9, Singapore, May 2010

Boileau S., Guipont V., Jeandin M., Nivard M., Berthe L., Jerome J., Boustie M., Li H., Khor K.A. (2005). The Laser Shock Adhesion (LASAT) for Production Control of Thermally-Sprayed Ceramic Coatings, Proceedings of Thermal Spray Connects: Explore its Surfacing Potential!, ISBN 3-87155-793-5, Basel, Switzerland, May, 2005

Boustie M., Auroux E., Romain J.P. (2000). Application of the Laser Spallation Technique to the Measurement of the Adhesion Strength of Tungsten Carbide Coatings on Superalloy Substrates, European Physical Journal-Applied Physics, Vol. 12, pp. 47-53

Brandt O.C. (1995), Mechanical properties of HVOF coatings, Journal of Thermal Spray Technology, Vol. 4, No. 2, pp. 147-152

Bray M., Cockburn A., O'Neil W. (2009). The Laser-assisted Cold Spray process and deposit characterization, Surface \& Coatings Technology, Vol. 203, pp. 2851-2857

Chavan N. M., Ramakrishna M., Sudharshan Phani P., Srinivasa Rao D., Sundararajan G. (2011). The influence of process parameters and heat treatment on the properties of cold sprayed silver coatings, Surface \& Coatings Technology, Vol. 205, No. 20, pp. 4798-4807

Christoulis D.K., Pantelis D.I., Borit F., Guipont V., Jeandin M. (2006). Effect of Substrate Preparation on the Flattening of Plasma Sprayed Aluminium Bronze Powders., Surface Engineering, Vol. 6, pp. 420-431

Christoulis D.K., Guetta S., Guipont V., Berger M.H., Jeandin M., Boustie M., Costil S., Ichikawa Y., Ogawa K., Irissou E., Legoux J.-G., Moreau C. (2009). Cold Spraying Combined to Laser Surface Pre-treatment using PROTAL®, Proceedings of the Expanding Thermal Spray Performance to New Markets and Applications, ISBN-13: 9781-61503-004-0, Las Vegas, United States of America, May, 2009

Christoulis D.K., Guetta S., Irissou E., Guipont V., Berger M.H., Jeandin M., Legoux J.-G., Moreau C., Ichikawa Y., Ogawa K., Costil S., Boustie M. (2010). Cold-Spraying Coupled to Nano-Pulsed Nd-YaG Laser Surface Pre-treatment, Journal of Thermal Spray Technology, Vol. 19, No. 5, pp.1062-1073.

Christoulis D.K., Guetta S., Guipont V., Jeandin M. (2011). The Influence of the Substrate on the Deposition of Cold-Sprayed Titanium: An Experimental and Numerical Study, Journal of Thermal Spray Technology, Vol. 20, No. 3, pp. 523-533

Costil S., Coddet C., Rosa G., Psyllaki P., Oltra R. (2001). Non Destructive testing for the Estimation of the Adhesion of Plasma Sprayed Coatings, Proceedings of News Surfaces for the New Millenium, ISBN 0-87170-737-3, Singapore, 2001

Costil S., Li H., Coddet C., Barnier V., Oltra R. (2004a). Role of Laser Surface Activation During Plasma Spray Coating of Metallic Materials, Proceedings of $18^{\text {th }}$ International 
Conference on Surface Modification Technologies, ISBN 0871708337, Dijon, France, November, 2004

Costil S., Li H., Coddet C. (2004b). New Developments in the PROTAL ${ }^{\circledR}$ Process, Proceedings of Thermal Spray 2004: Advances in Technology and Application, ISBN 0-87170-809-4, Osaka, Japan, May, 2004

Danlos Y., Costil S., Liao H., Coddet C. (2011). Influence of Ti-6Al-4V and Al 2017 substrate morphology on $\mathrm{Ni}-\mathrm{Al}$ coating adhesion - impacts of laser treatments, Surface $\mathcal{E}$ Coatings Technology, Vol. 205, No. 8-9, pp. 2702-2708.

Davis J. (2004). Handbook of Thermal Spray Technology, 2004, ASM International., ISBN 087170-795-0, United States of America

Day J., Huang X., RicFhards N.L. (2005), Examination of a Grit-Blasting Process for Thermal Spraying Using Statistical Methods, Journal of Thermal Spray Technology, Vol. 14, No. 4, pp 471-479.

Dorfman M.R., Nonni M., Mallon J., Woodard W., P. Meyer. (2004). Thermal Spray Technology Growth in Gas Turbine Coatings, Proceedings of Thermal Spray 2004: Advances in Technology and Application, ISBN 0-87170-809-4, Osaka, Japan, May, 2004

Dubourg L., Moreau C. (2006). Microstructure and Mechanical Properties of Yttria Partially Stabilized Zirconia Coatings Deposited by Laser-Assisted Air Plasma Spraying, Proceedings of Building on 100 Years of Success: Proceedings of the 2006 International Thermal Spray Conference, Seattle, United States of America, May, 2006

Evans B., Panza-Giosa R., Cochien Brikaras E., Maitland S. (2006). HVOF-Applied WC-CO$\mathrm{Cr}$ as a Hard Chrome Replacement for Landing Gear, Proceedings of Building on 100 Years of Success: Proceedings of the 2006 International Thermal Spray Conference, Seattle, United States of America, May, 2006

Fabre G., Guipont V., Jeandin M., Boustie M., Cuq-Lelandais J.P., Berthe L., Pasquet A., Guedou J-Y. (2011). LAser Shock Adhesion Test (LASAT) of Electron Beam Physical Vapor Deposited Thermal Barrier Coatings (EB-PVD TBCs), Advanced Materials Research, Vol. 278, pp. 509-514

Fukanuma H., Ohno N. (2003). Influences of Substrate Roughness and Temperature on Adhesive Strength in Thermal Spray Coatings, Proceedings of Thermal Spray 2003: Advancing the Science \& Applying the Technology, ISBN 0-87170-785-3, Orlando, United States of America, May 2003.

Gaffet E., Michel D., Mazerolles L., Berthet P., Effects of High Energy Ball Milling on Ceramic Oxides, Materials Science Forum, Vol. 235-238, pp. 103-108

Garcia-Alonso D., Serres N., Demian C., Costil S., Langlade C., Coddet C. (2011). Pre/During-/Post-Laser Processes to Enhance the Adhesion and Mechanical Properties of Thermal-Sprayed Coatings with a Reduced Environmental Impact, Journal of Thermal Spray Technology, 2011, Vol. 20, No. 11, pp. 719-735

Gartner F., Schmidt T., Stoltenhoff T., Kreye H. (2006). Recent developments and potential applications of cold spraying, Advanced Engineering Materials, Vol. 8, No. 7, pp. 611618

Gertsman V.Y,. Kwok Q.S.M. (2005). TEM Investigation of Nanophase Aluminum Powder, Microscopy and Microanalysis, Vol. 11, No. 5, pp. 410-420

Golesich B.T., Anderson K. (2008). Effects of Surface Preparation on the Performance of Cold Spray Coatings, Proceeding of $19^{\text {th }}$ AeroMat Conference E Exposition, 23-26 June 2008, Austin, Texas, USA 
Gonzalez-Hermosilla W.A., Chicot D., Lesage J., La Barbera-Sosa J.G., Gruescu I.C., Staia M.H., Puchi-Cabrera E.S. (2010). Effect of substrate roughness on the fatigue behavior of a SAE 1045 steel coated with a WC-10Co-4Cr cermet deposited by HVOF thermal spray, Materials Science and Engineering A,Vol. 527, pp. 6551-6561

Greving D.J., Shadley J.R., Rybicki E.F., Greving D.J., Shadley J.R., Rybicki E.F. (1994), Effects of coating thickness and residual stresses on the bond strength of ASTM C633-79 thermal spray coating test specimens, Journal of Thermal Spray Technology, Vol. 3, No. 4, pp. 371-378

Guetta S., Berger M.H., Borit F., Guipont V., Jeandin M., Boustie M., Ichikawa Y., Sakaguchi K., Ogawa K. (2009). Influence of Particle Velocity on Adhesion of Cold-Sprayed Splats, Journal of Thermal Spray Technology, Vol. 18, No. 3, 2009, pp. 331-342

Guipont V., Espanol M., Borit F., Llorca-Isern N., Jeandin M., Khor K.A., Cheang P. (2002). High-Pressure Plasma Spraying of Hydroxyapatite Powders, Materials Science and Engineering A, Vol. 25, No. 1-2, pp. 9-18

Hall A.C., Cook D.J., Neiser R.A., Roemer T.J., Hirschfeld D.A.. (2006). The effect of a simple annealing heat treatment on the mechanical properties of cold-sprayed aluminium, Journal of Thermal Spray Technology Vol. 15, No. 2, pp. 233-238

Hartmann S. (2010). New industrial applications for cold spraying, Proceedings of Thermal Spray: Global Solutions for Future Application, ISBN 978-3-87155-590-9, Singapore, May 2010

Ichikawa Y., Sakaguchi K., Ogawa K., Shoji T., Barradas S., Jeandin M., Boustie M. (2007a). Depostion mechanisms of cold gas dynamic sprayed MCrAlY Coatings, Proceedings of Thermal Spray 2007: Global Coating Solutions, ISBN 0-87170-809-4, Beijing, China, May 2007

Ichikawa Y., Barradas S., Borit F., Guipont V., Jeandin M., Nivard M., Berthe L., Ogawa K., Shoji T. (2007b). Evaluation of Adhesive Strength of Thermal-Sprayed Hydroxyapatite Coatings using the Laser Shock Adhesion Test (LASAT), Materials Transactions, Vol. 48, No. 4, pp. 793-798

Ichikawa Y., Miyazaki T., Ogawa K., Shoji T., Jeandin M., (2008). Deposition Mechanism of Cold Sprayed MCrAlY Coatings Focused on Nanostructure, Proceedings of Thermal Spray 2008: Thermal Spray Crossing Borders, ISBN: 978-3-87155-979-2, Maastricht, The Netherlands, June 2008

Irissou E., Arsenault B. (2007). Corrosion study of cold sprayed aluminum coatings onto Al 7075 alloy substrates, Proceedings of Thermal Spray 2007: Global Coating Solutions, ISBN 0-87170-809-4, Beijing, China, May 2007

Irissou E., Legoux J.G., Ryabinin A.N., Jodoin B., Moreau C. (2008a). Review on cold spray process and technology: Part I - Intellectual property, Journal of Thermal Spray Technology, Vol. 17, No. 4, pp. 495-516

Irissou E., Legoux J.-G., Moreau C., Ryabinin N. (2008b). How Cold is Cold Spray? An Experimental Study of the Heat Transfer to the Substrate in Cold Gas Dynamic Spraying, Proceedings of Thermal Spray 2008: Thermal Spray Crossing Borders, ISBN: 978-3-87155-979-2, Maastricht, The Netherlands, June, 2008

Jeandin M., Barradas S., Arrigoni M., He H.L., Boustie M., Bolis C., Berthe L. (2003). Thermal Spray and Lasers, Proceeding of the $2^{\text {nd }}$ International Conference on Materials Processing for Properties and Performance (MP3), Yokohama, Japan, October, 2003. 
Jeandin M., Christoulis D., Borit F., Berger M.H., Guetta S., Rolland G., Guipont V., Irissou E., Legoux J.G., Moreau C., Nivard M., Berthe L., Boustie M., Ludwig W., Sakaguchi K., Ichikawa Y., Ogawa K. Costil S. (2010). Lasers and Thermal Spray, Materials Science Forum, Vol.. 638-642, pp.171-184

Knapp W., Jeandin M., Behm V., Giraud D., Descurninges L.L., Guinard C., Zeralli Y., Christoulis D. (2011). Laser Structuring to improve cold-sprayed coating-substrate bond strength. Presented at 1st EUropean COLd Symposium (EUCOS 2011), Paris, France, May, 2011

Koivuluoto H., Lagerbom J., Vuoristo P. (2007). Microstructural Studies of Cold Sprayed Copper, Nickel, and Nickel-30\% Copper Coatings, Journal of Thermal Spray Technology, Vol. 16, No. 4, pp. 488-497

Koivuluoto H., Vuoristo P. (2010). Structural Analysis of Cold-Sprayed Nickel-Based Metallic and Metallic-Ceramic Coatings, Journal of Thermal Spray Technology, Vol. 19, No. 5, pp. 975-989

Kroemmer W., Heinrich P. (2006). Cold spraying-Potential and new application ideas, Proceedings of Building on 100 Years of Success: Proceedings of the 2006 International Thermal Spray Conference, Seattle, United States of America, May, 2006

Li W.-Y., Zhang C.,. Guo X. P, Dembinski L., Liao H.L., Coddet C., Li C.-J. (2007) Impact fusion of particle interfaces in cold spraying and its effect on coating microstructure, Proceedings of Thermal Spray 2007: Global Coating Solutions, ISBN 087170-809-4, Beijing, China, May 2007

Li W.-Y., Zhang C., Liao H., Li J., Coddet C. (2008). Characterizations of cold-sprayed Nickel-Alumina composite coating with relatively large Nickel-coated Alumina powder, Surface \& Coatings Technology, Vol. 202, pp. 4855-4860

Li P., Xi S., Zhou J. (2009). Phase Transformation and Gas-Solid Reaction of $\mathrm{Al}_{2} \mathrm{O}_{3}$ During High-Energy Ball Milling in N2 Atmosphere, Ceramics International, Vol. 35, No. 1, pp. 247-251

Liu X.-Y., Ding C.-X. Microstructure and Biological Properties of Plasma Sprayed Novel Bioactive Coatings, Proceedings of the Expanding Thermal Spray Performance to New Markets and Applications, ISBN-13: 978-1-61503-004-0, Las Vegas, United States of America, May, 2009

Lu S.P., Kwon O.Y. (2002). Microstructure and bonding strength of WC reinforced Ni-base alloy brazed composite coating, Surface E Coatings Technology, Vol. 153, No. 1, pp. 40-48

Makinen H., Lagerbom J., Vuoristo P. (2007). Adhesion of cold sprayed coatings: Effect of powder, substrate and heat treatment, Proceedings of Thermal Spray 2007: Global Coating Solutions, ISBN 0-87170-809-4, Beijing, China, May 2007

Marrocco T., McCartney D.G., Shipway P.H., Sturgeon A.J. (2006). Production of titanium deposits by cold gas dynamic spray: Numerical modelling and experimental characterization, Journal of Thermal Spray Technology, Vol. 15, No. 2 pp. 263-272.

McDonald A., Lamontagne M., Moreau C., Chandra S. (2006). Impact of plasma-sprayed metal particles on hot and cold glass surfaces, Thin Solid Films, Vol. 514, pp. 212-22

Moreau C, Gougeon P., Lamontagne M., (1995). Influence of Substrate Preparation on the Flattening and Cooling of Plasma-Sprayed Particles, Journal of Thermal Spray Technology, Vol. 4 No. 1, 1995, pp. 25-33. 
Padture N.P, Gell M., Jordan E.H. (2002). Thermal barrier coatings for gas-turbine engine applications, Science, Vol. 296, No. 5566, pp. 280-284

Papyrin A., Kosarev V., Klinkov S., Alkhimov A., Fomin V. (2007), Cold Spray Technology, Elsevier Ltd, ISBN: 978-0-08-045155-8, The Netherlands

Paredes R.S.C., Amico S.C., d'Oliveira A.S.C.M. (2006). The effect of roughness and preheating of the substrate on the morphology of aluminium coatings deposited by thermal spraying, Surface \& Coatings Technology, Vol. 200, pp. 3049 - 3055

Petavratzi E., Kingman S., Lowndes I. (2005). Particulates from Mining Operations: A Review of Sources, Effects and Regulations, Minerals Engineering, Vol. 18, No. 12, pp. 1183-1199.

Price T.S., Shipway P.H., McCartney D.G. (2006). Effect of Cold Spray Deposition of a Titanium Coating on Fatigue Behavior of a Titanium Alloy, Journal of Thermal Spray Technology, Vol. 15, pp. 507-512

Richer P., Jodoin B., Ajdelsztajn L., Lavernia E.J. (2006). Substrate Roughness and Thickness Effects on Cold Spray Nanocrystalline Al-Mg Coatings, Journal of Thermal Spray Technology, Vol. 15, No. 6, pp. 246-254

Sarafoglou Ch.I., Pantelis D.I., Beauvais S., Jeandi M. (2007). Study of Al2O3 coatings on AISI 316 stainless steel obtained by controlled atmosphere plasma spraying (CAPS), Surface \& Coatings Technology, Vol. 202, No. 1, pp. 155-161

Saral U., Toplan N. (2009) Thermal cycle properties of plasma sprayed YSZ/Al2O3 thermal barrier coatings, Surface Engineering, Vol. 25, No. 7, pp. 541-547

Schlaefer T., Bobzin K., Ernst F., Richardt K., Verpoort C., Schreiber A., Schwenk A., Flores G. (2008). Plasma transferred wire arc spraying of novel wire feedstock onto cylinder bore walls of AlSi engine blocks, Proceedings of Thermal Spray 2008: Thermal Spray Crossing Borders, ISBN: 978-3-87155-979-2, Maastricht, The Netherlands, June 2008

Schmidt T., Assadi H., Gartner F., Richter H., Stoltenhoff T., Kreye H., Klassen T. (2009). From Particle Acceleration to Impact and Bonding in Cold Spraying, Journal of Thermal Spray Technology, Vol. 18, No. 5-6, pp. 794-808

Shin S., Xiong Y., Ji Y., Kim H.J., Lee C. (2008). The influence of process parameters on deposition characteristics of a soft/hard composite coating in kinetic spray process, Applied Surface Science, Vol. 254, No. 8, pp. 2269-2275

Stoltenhoff T., Borchers C., Gartner F., Kreye H. (2006). Microstructures and key properties of cold-sprayed and thermally sprayed copper coatings, Surface $\mathcal{E}$ Coatings Technology, Vol. 200, No. 16-17, pp. 4947-4960

Spencer K., Zhang M.-X. (2009). Heat treatment of cold spray coatings to form protective intermetallic layers, Scripta Materialia, Vol. 61, pp. 44-47

Sundararajan G., Chavan N. M., Sivakumar G., Sudharshan Phani P. (2010). Evaluation of Parameters for Assessment of Inter-Splat Bond Strength in Cold-Sprayed Coatings, Journal of Thermal Spray Technology, Vol. 19, No. 6, pp. 1255-1266

Taylor, T.A. (1995). Surface roughening of metallic substrates by high pressure pure waterjet, Surface \& Coatings Technology, Vol. 76-77, pp. 95-100.

Triantou K. I., Sarafoglou Ch. I., Pantelis D.I., Christoulis D.K., Guipont V., Jeandin M., Zaroulias A., Vardavoulias M. (2008) A Microstructural Study of Cold Sprayed Cu Coatings on 2017 Al Alloy, Proceedings of Thermal Spray 2008: Thermal Spray Crossing Borders, ISBN: 978-3-87155-979-2, Maastricht, The Netherlands, June 2008 
Tollier L., Fabbro R., Bartnicki E. (1998a). Study of the laser driven spallation process by the velocity interferometer system for any reflector interferometry technique. I. laser shock characterization, Journal of Applied Physics, Vol. 83, No. 3, pp. 1224-1230

Tollier L., Fabbro R., Bartnicki E. (1998b). Study of the laser driven spallation process by the velocity interferometer system for any reflector interferometry technique. II. Experiment and simulation of the spallation process, Journal of Applied Physics, Vol. 83, No. 3, pp. 1231-1237

Van-Steenkiste T.H., Smith J.R., Teets R.E., Moleski J.J., Gorkiewicz D.W., Tison R.P., Marantz D.R., Kowalsky K.A., Riggs W.L., Zajchowski P.H., Pilsner B., McCune R.C., Barnett K.J. (1999). Kinetic spray coatings, Surface \& Coatings Technology, Vol. 111, pp. 62-71.

Van-Steenkiste T.H., Smith J.R., Teets R.E. (2002). Aluminum coatings via kinetic spray with relatively large powder particles, Surface \& Coatings Technology, Vol.154, pp. 237252.

Wong W., Irissou E., Ryabinin A. N., Legoux J.-G., Yue S. (2011), Influence of Helium and Nitrogen Gases on the Properties of Cold Gas Dynamic Sprayed Pure Titanium Coatings, 2011, Journal of Thermal Spray Technology, Vol. 20, No. 1-2, pp. 213-226

Xiong Y., Kang K., Bae G., Yoon S., Lee C. (2008). Dynamic Amorphization and Recrystallization of Metals in Kinetic Spray Process, Applied Physics Letters, Vol. 92, No. 19, pp. 19401-19404

Zhang D., Shipway P.H., McCartney D.G. (2003). Particle-substrate interactions in cold gas dynamic spraying Proceedings of Thermal Spray 2003: Advancing the Science $\mathcal{E}$ Applying the Technology, ISBN 0-87170-785-3, Orlando, United States of America, May 2003.

Zhang J., Xu N., Hou W.L., Wang J.Q., Quan M.X., Chang X.C. (2009), Fabrication and Property of MCrAlY/Nanostructured YSZ Thermal Barrier Coating, Proceedings of the Expanding Thermal Spray Performance to New Markets and Applications, ISBN-13: 978-1-61503-004-0, Las Vegas, United States of America, May, 2009

Zecchino M. (2003). Why Average Roughness is Not Enough, Advance Materials \& Processes, Vol. 161, No. 3, pp.25-28

Zieris R., Nowotny S., Berger L.-M., Haubold L., Beyer E. (2003). Characterization of Coatings Deposited by Laser-Assisted Atmospheric Plasma Spraying, , Proceedings of Thermal Spray 2003: Advancing the Science \& Applying the Technology, ISBN 087170-785-3, Orlando, United States of America, May 2003.

Zieris R, Langner G., Berger L.-M., Nowotny S., Beyer E. (2004). Investigation of AlSi coatings prepared by laser-assisted atmospheric plasma spraying of internal surfaces of tubes, Proceedings of Thermal Spray 2004: Advances in Technology and Application, ISBN 0-87170-809-4, Osaka, Japan, May, 2004 